\title{
Evaluation of East Asian Meiyu from CMIP6/AMIP Simulations
}

Mingjun Tong ( $\square$ tongmy15@lzu.edu.cn )

Lanzhou University https://orcid.org/0000-0002-0692-5050

\section{Zhihai Zheng}

China Meteorological Administration

Qiang Fu

University of Washington

\section{Research Article}

Keywords: Meiyu, CMIP6, El Niño, IOBM

Posted Date: January 18th, 2022

DOl: https://doi.org/10.21203/rs.3.rs-919024/v1

License: (1) This work is licensed under a Creative Commons Attribution 4.0 International License.

Read Full License

Version of Record: A version of this preprint was published at Climate Dynamics on April 16th, 2022. See the published version at https://doi.org/10.1007/s00382-022-06218-z. 


\title{
Evaluation of East Asian Meiyu from CMIP6/AMIP Simulations Mingjun Tong ${ }^{1}$, Zhihai Zheng ${ }^{2, *}$, and Qiang $\mathbf{F u}^{3}$
}

${ }^{1}$ College of Atmospheric Sciences, Lanzhou University, Lanzhou, China

${ }^{2}$ National Climate Center, and Laboratory for Climate Studies, China Meteorological Administration, Beijing, China

${ }^{3}$ Department of Atmospheric Sciences, University of Washington, Seattle, WA, USA

Corresponding author: Zhihai Zheng (zhengzh@cma.gov.cn)

10

\begin{abstract}
East Asian Meiyu simulated by 35 global atmospheric models from the $6^{\text {th }}$ Coupled Model Intercomparison Project (CMIP6) / Atmospheric Model Intercomparison Project (AMIP) were systematically evaluated for 1998-2014. The results show that most of the CMIP6/AMIP model can hardly reproduce the observed spatial pattern and interannual variability of East Asian Meiyu. The spatial pattern is relatively better simulated over Southern Korea and Japan where 14 out of 35 models have realistically simulated precipitation, as compared with the lower reaches of the Yangtze River where only 7 out of 35 models can well reproduce the Meiyu precipitation. For the Meiyu interannual variations, GFDL-CM4 and GFDL-ESM4 have the closest variance among the models versus the TRMM observations, while 12 out of 35 models show smaller variances. We explored the relationships of Meiyu precipitation with large-scale circulation and tropical sea surface temperature (SST), and showed that these relationships from CESM2-WACCM-FV2, EC-Earth3-CC, and MPI-ESM1-2-HAM agree well with those based on TRMM precipitation, MERRA2 reanalysis-derived large-scale atmospheric fields, and observed SST. It is found that the models with a better simulation of Meiyu precipitation can capture the relationship between Meiyu precipitation and the SST in the eastern equatorial Pacific and Indian Ocean more
\end{abstract}


realistically. A performance ranking of the 35 individual CMIP6/AMIP models is further provided. It is shown that the top $20 \%$ of models based on interannual variability score (IVS) tend to simulate a more realistic western Pacific subtropical high than the bottom $20 \%$ of models. And the top $20 \%$ of models based on comprehensive ranking measure (CRM) simulate a more realistic EAP pattern than the bottom $20 \%$ of models.

Key words: Meiyu, CMIP6, El Niño, IOBM

\section{Introduction}

As an important component of the East Asian Summer Monsoon (i.e., EASM), the East Asian Meiyu is controlled by the EASM system moving over different latitudes, which is quite different from South Asian Summer Monsoon (e.g., Ding, 1992, 2004, 2020; Lau et al., 2000; Tao \& Chen, 1987). With a gradual northward propagation of EASM from June to July, the Meiyu rainband presents quasi-stationary characteristics tilting from lower reaches of the Yangtze River Basin of China (i.e., LYRB) to the central North Pacific (e.g., Ding \&Chan, 2005; Tao \& Chen, 1987; Wang et al., 2021; Tong et al., 2021). The record-breaking rainfall along the Yangtze River Basin in 2020 persisted for 62 days, induced by the Northwest Pacific anomalous anticyclone and intensified westerly jet due to the Indian Ocean warming, as well as anomalous SST in tropical Atlantic, eastern Pacific, and the Arctic sea ice (e.g., Zhou et al., 2021; Qiao et al., 2021; Pan et al., 2021; Tang et al., 2021; Chen et al., 2021). The duration and intensity of Meiyu precipitation, which is often related to floods and droughts in LYRB, southern Korea Peninsula, and southern Japan (i.e., K\&J), have an important impact on socioeconomic conditions in such regions (e.g., Ding et al., 2020).

Although the Coupled Model Inter-comparison Project (i.e., CMIP) has evolved to the sixth phase, there are still three central points of the project: How do the Earth system models respond to climate forcing? Where do the model errors originate from? What is the projected climate change like using an ever-expanding range of climate models? (e.g., Eyring et al., 2016). To better answer these questions, the World Climate 
Research Programme (WCRP) has organized DECK (Diagnostic, Evaluation, and Characterization of Klima), historical simulations, and 23 CMIP-Endorsed Model Intercomparison Projects (MIPs) to compare and analyze the models' simulations (e.g., Dong et al., 2021; Eyring et al., 2016; Stouffer et al., 2017; Zhou et al., 2019). The historical Atmospheric Model Intercomparison Project (AMIP) simulation is one of the four DECK experiments, which plays the role of a benchmark for other MIPs. However, the performance of AMIP in the latest suite of CMIP remains to be explored. For example, it is recognized that AMIP models overestimate precipitation over the western Pacific, which is probably related to the deficiencies in deep convection parameterizations (e.g., Li et al., 2017).

Extensive studies have been done to evaluate the fidelity of the state-of-the-art CMIP6 models from the perspective of precipitation (e.g., Choudhury et al., 2021; Coppola et al., 2021; Darshana et al., 2022; Dong et al., 2021; Fu et al., 2020; Na et al., 2020; Rajendran et al., 2021; Wang et al., 2021; Zhou et al., 2020). Dong et al (2021) assessed seven extreme precipitation indices from CMIP6, and compared them with those in CMIP5. It was found that the dry and wet biases in southern China and Tibet were reduced in CMIP6 models. Norris et al. (2021) unraveled the model spread in atmospheric conditions associated with extreme precipitation in California, showing an overestimation of integrated vapor transportation in most of the CMIP6 models. While many studies examined whether the CMIP6 models can reproduce observed extreme precipitation regionally and globally, little attention has been given to the performance of East Asian Meiyu across models.

80 In evaluating the model simulations of Meiyu, it is necessary to examine the related atmospheric processes. Wang et al. (2021) indicated that the discrepancies in precipitation between CMIP6/AMIP simulations and observations is related to the underestimation of mass stream function. They also suggested that the precipitation biases in CMIP6/AMIP probably resulted from the inaccurate precipitation responses to the warm sea. Since the CMIP models are not forced by the observed SSTs as the AMIP models (e.g., Eyring et al., 2016), the model-simulated SST interannual 
variability could affect the skill of simulated precipitation as compared with observations (e.g., Fu et al., 2020; Wang et al., 2021). As mentioned above, the 2020 summer Meiyu was marked as extremely strong rainfall, which can trace to the recordbreaking deepened thermocline in late 2019 (e.g., Zhou et al., 2021). Zhou et al. (2021) pointed out that the anomalous thermocline maintained the Indian Ocean anomalous warming, which is an important trigger for the formation of super Meiyu in 2020. Thus, how Meiyu responds to the Indian Ocean warming in the model simulations is essential to be confirmed.

Considering that little has been done to evaluate the CMIP6/AMIP simulated Meiyu precipitation systematically, this study evaluates the CMIP6/AMIP Meiyu precipitation using Tropical Rainfall Measuring Mission (i.e., TRMM) satellite product along with Modern-Era Retrospective Analysis for Research and Applications Version 2 ((MERRA2). The Meiyu-related atmospheric conditions and Meiyu precipitation responses to the ENSO-related SSTs and Indian Ocean warming are also examined. We organize the paper as follows. Section 2 introduces data and methods. The assessment of the Meiyu climatology and interannual variability from 35 individual CMIP6/AMIP models is presented in Section 3. The roots for better simulated climatology and interannual variation are explored in Section 4. The summary and discussions are provided in Section 5.

\section{Data and Methods}

\subsection{Observational and reanalysis datasets}

We used daily precipitation product from the Tropical Rainfall Measuring Mission (TRMM) and Other Satellites Precipitation Product (3B42) Version 7 (i.e., TRMM 3B42-V7), which combined multi-satellite precipitation data sets and gauge analyses with a spatial resolution of $0.25^{\circ} \times 0.25^{\circ}$ (e.g., Huffman et al., 2007). The main goal of TRMM is to analyze and understand tropical precipitation since it was launched in 1997, as well as its effects on the global climate (e.g., Simpson et al., 1998; Wolff et al., 2005). Many studies have demonstrated the reliability of TRMM precipitation, and shown that 
precipitation from TRMM 3B42 agrees well with the surface-based observations (e.g., Islam et al., 2007; Ouma et al., 2012). By examining the Meiyu characteristics using two observational products and four reanalyses, Tong et al. (2021) recommended that TRMM product and MERRA2 reanalysis should be used for the investigations of the Meiyu precipitation and variability and large-scale conditions. Thus, TRMM precipitation data are utilized as a benchmark in this study to evaluate precipitation simulated from CMIP6. The study period is from 1998-2014.

The Modern-Era Retrospective Analysis for Research and Applications, Version 2 (i.e., MERRA2) is endorsed by the National Aeronautics and Space Administration (i.e., NASA), aiming to enhance the fidelity of atmospheric reanalysis data (e.g., Decker et al., 2011; Gelaro et al., 2017). MERRA2 covers the period from 1980 to the present, with a horizontal resolution of $0.625^{\circ} \times 0.5^{\circ}$. The data set is available from GES DISC Search: Showing 1 - 25 of 99 datasets (nasa.gov).

\subsection{CMIP6/AMIP data}

130 We used the AMIP runs from CMIP6 models, which are available at cmip6 Data Search L cmip6 | ESGF-CoG (llnl.gov). The variables include daily precipitation, 850-hPa monthly winds, and 500-hPa geopotential heights. The detailed information of CMIP6/AMIP models used in this study is given in S-Table 1. All available realizations from each model are averaged to reduce the impact of atmospheric internal variabilities among different realizations (e.g., Wang et al., 2011). The CMIP6/AMIP models have coarser resolutions than TRMM and MERRA2, and we have regridded the model outputs to finer resolutions for evaluation following previous studies (e.g., Dong et al., 2021; Jian et al., 2021). In particular, all the model outputs were regridded to a $0.25^{\circ} \times 0.25^{\circ}$ and a $0.625^{\circ} \times 0.5^{\circ}$ grids for a comparison with TRMM and MERRA2, respectively using the method described in Section 2.3. All the AMIP models are forced by the observed SST and sea ice concentration using the Hadley-OI dataset that is available at Dataset: Merged Hadley-OI Sea surface temperature and sea ice concentration data set (ucar.edu). We choose June 1 to July 31 each year as the Meiyu season (Tong et al. 2021). The seventeen-year Meiyu season from 1998 to 2014 is 
studied in this paper.

\subsection{Analysis Methodologies}

We used the following metrics to evaluate CMIP6/AMIP models in simulating Meiyu precipitation.

\subsubsection{Basic statistics}

The average precipitation $(\bar{x})$ during the Meiyu season from 1998 to 2014 at a certain grid is

$$
\bar{x}=\frac{1}{N} \sum_{i=1}^{N} X_{i},
$$

where $X_{i}$ is the daily precipitation for a certain day and $\mathrm{N}$ is the total number of days during the Meiyu season for 1998-2014.

155 The variance (S) is calculated as follows:

$$
S=\sqrt{\frac{1}{N-1} \sum_{i=1}^{N}\left(X_{i}-\bar{x}\right)^{2}} .
$$

\subsubsection{Regridding}

We applied the Natural Neighbor Interpolation method developed by Robin Sibson (e.g., Sibson., 1981). This approach finds the subset of input samples closest to the query point and interpolates these samples by applying weights to them proportionally based on the region size. The Natural Neighbor Interpolation method does not generate maximums and minimums that do not exist in the inputs. Thus, it is a relative interpolator among regridding methods (e.g., Hofstra et al., 2008). This toolbox is available in MATLAB.

\subsubsection{Taylor diagram}

Taylor diagrams are utilized to statistically examine the performance of climate models in terms of patterns' correlation, the difference of root mean square, and variances (e.g., Taylor, 2001). For our application, the angles in the diagram represent the correlation coefficients between the spatial distribution of Meiyu precipitation simulated by CMIP6/AMIP models and TRMM precipitation. Taylor diagrams also show the information of root mean square (RMS) differences (green circle), as well as the 
standard deviations by individual points (e.g., Taylor. 2011). By giving these three fundamental statistics, Taylor diagrams provide insights on how well models can simulate the Meiyu precipitation. In the Taylor diagram, the closer the point to the reference point (TRMM) indicates a better model simulation.

\subsubsection{Interannual Variability Score (IVS)}

Chen et al. (2011) put forward a new metric to calculate the ability of models in simulating the interannual variability, that is:

$$
I V S=\left(\frac{S T D_{\text {models }}}{S T D_{\text {ref }}}-\frac{S T D_{\text {ref }}}{S T D_{\text {models }}}\right)^{2},
$$

180 where $S T D_{\text {models }}$ indicates the standard deviation of CMIP6/AMIP models, and $S T D_{\text {ref }}$ is the standard deviation of TRMM precipitation. The smaller the IVS is, the better the models simulate the interannual variability.

\subsubsection{Comprehensive Ranking Measure (CRM)}

CRM, which reflects the overall performance of CMIP6/AMIP models, can be expressed as follows:

$$
C R M=1-\frac{1}{I * J} \sum_{i=1}^{I} \operatorname{Rank}_{i}(J) .
$$

Here, $\operatorname{Rank}_{i}(J)$ is the rank of 35 CMIP6/AMIP models. " $I$ " refers to the number of models. "J" refers to the number of indices (PCC in the Taylor diagram and IVS). The closer CRM is to 1, the better the simulation of the climate model's skill is (e.g.,Li et 190 al., 2015).

\section{The climatology and interannual variation of Meiyu from 35 individual CMIP6/AMIP models}

\subsection{The climatology features of Meiyu across CMIP6/AMIP models.}

The mean daily Meiyu precipitation during the Meiyu season from TRMM is given in

Figure 1 (a), which shows the inclined Meiyu rainband, titling from the LYRB region to the central north Pacific. Two large rainfall centers are located in the LYRB and southern Korea and Japan (i.e., K\&J). We define the Meiyu Area as the region between $28^{\circ} \mathrm{N}-36^{\circ} \mathrm{N}$ and $110^{\circ} \mathrm{E}-140^{\circ} \mathrm{E}$ (Tong et al. 2021). 
As shown in Figure 2, most of the CMIP6/AMIP models underestimate the magnitude of Meiyu precipitation compared to TRMM (Figure 1 (a)). As for the two centers of Meiyu precipitation, there are 14 out of 35 models more realistically reflecting rainfall in K\&J, including ACCESS-CM2, ACCESS-ESM1-5, EC-Earth3, EC-Earth3-CC, EC-Earth3-Veg, INM-CM4-8, INM-CM5-0, IPSL-CM6A-LR, MIROC6, MPI-ESM1-2-HR, MRI-ESM2-0, NESM3, SAM0-UNICON, and TaiESM1. Meanwhile, only 7 out of 35 models including ACCESS-CM2, CMCC-CM2-SR5, IPSL-CM6A-LR, MPI-ESM-1-2-HAM，MPI-ESM1-2-HR，MPI-ESM1-2-LR, and SAM0-UNICON can reasonably simulate precipitation in the LYRB. According to Figure S1, EC-Earth3, EC-Earth3-AerChem, EC-Earth3-CC, EC-Earth3-Veg, and MRI-ESM2-0 have relatively small precipitation biases with respect to TRMM during the Meiyu season.

The evolution of the Meiyu rainband during the Meiyu season is shown in Fig.3 for TRMM and 35 CMIP6/AMIP models. EC-Earth3-CC, EC-Earth3-Veg, and SAM0UNICON perform better in simulating the advancing northward Meiyu rainband than the other models with somewhat underestimation in magnitude. Most of the CMIP6/AMIP models fail to capture the characteristic of the retreat of Meiyu rainband in mid-July.

To quantify the models' performance in simulating Meiyu precipitation during the Meiyu season for 1998-2014 versus TRMM, Taylor diagrams are shown in Figure 4 over K\&J, LYRB and entire Meiyu regions. It is found that pattern correlation coefficients vary among regions. All correlation coefficients are positive in the K\&J region, and the correlation coefficients are overall positive for the entire Meiyu area except for NorCPM1 and BCC-ESM1, while 5 out of 35 CMIP6/AMIP models show negative values in the LYRB region. CMIP6/AMIP models thus can reproduce the Meiyu precipitation better in K\&J than that in LYRB, which is consistent with the results shown in Figure 2.

\subsection{The interannual variation of Meiyu across CMIP6/AMIP models.}

CMIP6 models display some skills in simulating interannual variability of precipitation 
(e.g., Kosaka et al., 2021). Figure 1 (b) shows that precipitation variance over southern Korea and Japan is larger than that in the Yangtze River Basin. Figure 5 shows that GFDL-CM4 and GFDL-ESM4 have the closest variance to TRMM among the models, while CAMS-CSM1-0, CanESM5, CMCC-CM2-HR4, CMCC-CM2-SR5, four ECMWF models, INM-CM4-8, INM-CM5-0, MPI-ESM-1-2-HAM, MPI-ESM1-2-HR, and MRI-ESM2-0 show smaller variances. Meanwhile, ACCESS-ESM1-5, FGOALSg3, NorCPM1, and NorESM2-LM can hardly reflect the variance pattern from TRMM.

Time series of the precipitation anomalies from the 35 individual CMIP6/AMIP models in the Meiyu Area are shown versus that from TRMM in Figure 6(a). The TRMM precipitation anomalies are within the range of the 35 CMIP6/AMIP simulations, while the AMIP model mean anomalies fail to capture the overall interannual variability of TRMM precipitation. Figure 6(b) shows the IVS for all the 35 AMIP models. The smaller the IVS is, the better the interannual variability is simulated. MPI-ESM1-2-HR and FGOALS-G3 have relatively higher IVS, indicating that these two models perform worst in simulating interannual variabilities.

According to Figure 4, we count the ranking of pattern correlation coefficients among CMIP6/AMIP models (Table 1), as well as IVS and Comprehensive Ranking Measure (CRM). The first 7 and last 7 models listed in Table 1, which are in bold font, represent the Top $20 \%$ and Bottom 20\% of CRM rankings, respectively. The CRM ranking is the overall ranking of all the models considering both the climatology and the interannual variability of Meiyu. The Top 20\% models of CRM in this study include MRI-ESM20, EC-Earth3-CC, EC-Earth3, ACCESS-ESM1-5, EC-Earth3-Veg, MIROC6, 250 andGFDL-ESM4. The 7 Bottom 20\% models are FGOALS-G3, BCC-ESM1, TaiESM1, INM-CM-4-8, MPI-ESM1-LR, CMCC-CM2-HR4, and NorCPM1. However, the ability to reproduce Meiyu's climatology and interannual variability may differ greatly from models. Thus, the top 7 and last 7 models in IVS ranking also need to be considered in the following discussion, especially on the relationship between Meiyu precipitation and ENSO/IOBM (Section 4.2). 
Table 1. The ranking of CMIP6/AMIP models' Comprehensive Ranking Measure (CRM)

\begin{tabular}{|c|c|c|c|}
\hline Ranking & PCC & IVS & CRM \\
\hline MRI-ESM2-0 & 1 & 3 & 0.94 \\
\hline EC-Earth3-CC & 5 & 4 & 0.87 \\
\hline EC-Earth3 & 6 & 7 & 0.81 \\
\hline ACCESS-ESM1-5 & 11 & 2 & 0.81 \\
\hline EC-Earth3-Veg & 8 & 8 & 0.77 \\
\hline MIROC6 & 15 & 5 & 0.71 \\
\hline GFDL-ESM4 & 3 & 18 & 0.70 \\
\hline FGOALS-f3-L & 13 & 10 & 0.67 \\
\hline IPSL-CM6A-LR & 10 & 14 & 0.66 \\
\hline CESM2 & 19 & 6 & 0.64 \\
\hline NorESM2-LM & 24 & 1 & 0.64 \\
\hline ACCESS-CM2 & 2 & 24 & 0.63 \\
\hline GFDL-CM4 & 9 & 17 & 0.63 \\
\hline SAM0-UNICON & 14 & 12 & 0.63 \\
\hline EC-Earth3-AerChem & 4 & 23 & 0.61 \\
\hline NESM3 & 16 & 11 & 0.61 \\
\hline BCC-CSM2-MR & 17 & 15 & 0.54 \\
\hline CESM2-WACCM & 23 & 9 & 0.54 \\
\hline CESM2-WACCM-FV2 & 22 & 13 & 0.50 \\
\hline MPI-ESM1-2-HR & 7 & 30 & 0.47 \\
\hline CAMS-CSM1-0 & 12 & 29 & 0.41 \\
\hline INM-CM5-0 & 26 & 16 & 0.40 \\
\hline CanESM5 & 18 & 27 & 0.36 \\
\hline KIOST-ESM & 20 & 26 & 0.34 \\
\hline IITM-ESM & 25 & 22 & 0.33 \\
\hline CMCC-CM2-SR5 & 30 & 19 & 0.30 \\
\hline
\end{tabular}




\begin{tabular}{llll} 
MPI-ESM-HAM & 27 & 25 & 0.26 \\
CESM2-FV2 & 32 & 20 & 0.26 \\
FGOALS-G3 & 21 & 34 & 0.21 \\
BCC-ESM1 & 34 & 21 & 0.21 \\
TaiESM1 & 29 & 28 & 0.19 \\
INM-CM-4-8 & 31 & 31 & 0.11 \\
MPI-ESM1-LR & 28 & 35 & 0.10 \\
CMCC-CM2-HR4 & 33 & 33 & 0.06 \\
NorCPM1 & 35 & 32 & 0.04 \\
\hline
\end{tabular}

\section{The roots for better Meiyu simulation in CMIP6/AMIP models}

\subsection{Climatology}

Takaya et al. (2020) indicated that the inflexible trough over the Yellow Sea, strong subtropical jet, and subtropical high extending to the southwest compose the essential factors of extreme rainfall events. Therefore, we explore the relationship between the Meiyu precipitation averaged over the Meiyu area and 500-hPa geopotential height (Figure 7), and 200-hPa zonal wind (Figure 8). According to the TRMM\&MERRA2 result (Figure 7a), negative correlations over the Yellow Sea (around $125^{\circ} \mathrm{E}$ ) indicate that there is a trough located over the areas associated with larger averaged Meiyu precipitation. Overall, the pattern of relationship between the averaged Meiyu precipitation and the $500-\mathrm{hPa}$ geopotential height is similar to the East Asia/Pacific (EAP) teleconnection, which has crucial influences on East Asian summer rainfall. In East Asia, the circulation distribution of EAP related to Meiyu is "positive-negativepositive" (i.e., the negative phase of EAP) from low latitude to high latitude, which are located in the South China Sea and the Philippines, Japan, and the area near the Sea of

275 Okhotsk respectively (e.g., Yang et al 2018; Chen at al., 2019). From the perspective of the location of EAP centers, CESM2-WACCM, CESM2-WACCM-FV2, CMCC-CM2SR5, EC-Earth3, EC-Earth3-CC, EC-Earth3-Veg, IPSL-CM6A-LR, MPI-ESM1-2HAM, and NorESM2-LM can reasonably reproduce the EAP center located in the 
South China Sea, and most of the CMIP6/AMIP models successfully capture the EAP center in the mid to high latitudes. Figure S2 shows that the Top $20 \%$ models in CMIP6/AMIP give excellent expression to the two EAP centers in low-mid latitudes, while the Bottom $20 \%$ models fail in this aspect. In addition, the position of western subtropical high influences the intensity of East Asian precipitation (e.g., $\mathrm{Xu}$ et al., 2020). EC-Earth3-CC, EC-Earth3-Veg, FGOALS-f3-L, FGOALS-g3, MIROC6, MPIESM1-2-HAM, and MPI-ESM1-2-HR agree well with the relationship derived from the MERRA2 500-hPa geopotential height and the TRMM Meiyu precipitation.

The westerly jet is a crucial factor for Meiyu. (e.g., Sampe and Xie, 2010). Horinouchi et al. (2019) revealed that the meridional locations of the subtropical jet are correlated to Meiyu precipitation positively. Figure 8 shows the relationship between the subtropical jet and Meiyu precipitation averaged over the Meiyu region from TRMM\&MERRA2 and 35 CMIP6/AMIP models, which varies largely across models. BCC-CSM2-MR, CAMS-CSM1-0, CESM2, CESM2-WACCM, EC-Earth3, ECEarth3-CC, EC-Earth3-Veg, and MPI-ESM1-2-LR have overestimations of the intensity of subtropical jet. Meanwhile, CESM2-WACCM-FV2, EC-Earth3-CC, and MPI-ESM1-2-HAM perform better than other atmospheric models in simulating this relationship. Figure $\mathrm{S} 3$ shows that the Top $20 \%$ of models in CMIP6/AMIP can simulate a more realistic EAP pattern than the Bottom $20 \%$ of models.

\subsection{Interannual variation}

As the East Asian summer monsoon is strongly influenced by ENSO events, how the relationship between the SST in pre-winter season and averaged Meiyu precipitation during the Meiyu season is reproduced in the CMIP6/AMIP models needs to be examined. Figure 9 clearly shows that Meiyu precipitation and SSTs in the equatorial eastern Pacific Ocean during the previous winter are significantly and positively correlated from observations (Fig. 9a), ACCESS-ESM1-5, CAMS-CSM1-0, CanESM5, CESM2-WACCM, EC-Earth3, EC-Earth3-CC, MPI-ESM-1-2-HAM, MRI-ESM2-0, and NorESM2-LM. Such positive SST anomalies in the eastern equatorial Pacific can induce remarkable atmospheric heating anomalies, which can enhance the westerly 
wind anomalies through the Gill-type atmospheric response (e.g., Chen et al., 2014; Gill 1980; Xie and Philander 1994; Vimont et al., 2003; Wang et al., 2021). The

310 intensities of the correlation between averaged precipitation and pre-winter SSTs vary from different models. ACCESS-ESM1-5, CAMS-CSM1-0, CanESM5, CESM2WACCM, CMCC-CM2-SR5, EC-Earth3, EC-Earth3-CC, FGOALS-f3-L, IITM-ESM, IPSL-CM6A-LR， MPI-ESM1-2-HAM， MPI-ESM1-2-LR， MRI-ESM2-0， and TaiESM1 significantly overestimated this relationship, while ACCESS-CM2, BCCCSM2-MR, CESM2, CESM2-FV2, CESM2-WACCM-FV2, CMCC-CM2-HR4, ECEarth3-AerChem, INM-CM4-8, INM-CM5-0, KIOST-ESM, NESM3 underestimated the relationship. Because ENSO is an interannual signal, we select the Top 20\% and the Bottom 20\% models here based on the ranking of IVS in Table 1, which is the corresponding ranking of interannual variabilities of CMIP6/AMIP models. The Top $20 \%$ models show more significantly positive correlations than the Bottom $20 \%$ CMIP6/AMIP models in the equatorial eastern Pacific Ocean during the previous winter (Figure S4).

Based on the Climate Prediction Center standard, we selected El Niño years (1998, 2003, 2005, 2007, and 2010) and La Niña years (1999, 2000, 2001, 2006, 2008, 2009, 2011, and 2012). Figure 11 (a), (c), and (e) show the differences in circulation fields between strong El Niño years and strong La Niña years during the Meiyu season. Since ENSO is an interannual signal, the Top 20\%, and Bottom 20\% models in AMIP are selected based on IVS ranking from Table 1. As compared to the MERRA2 results, the Top 20\% models can simulate a more realistic subtropical high than the Bottom $20 \%$ of models, and with a closed center of the subtropical high located in the eastern Pacific Ocean as the MERRA2 dataset.

The basin-wide warming over the Indian Ocean is followed by an El Niño event (e.g., Xie et al., 2016), and persists into East Asian summer. Many studies have shown that the Indian Ocean warming tends to bring more precipitation to East Asian summer.

335 Thus, it is necessary to evaluate whether the relationship between spring Indian Ocean SSTs and Meiyu precipitation is simulated realistically. Figure 10 helps us answer this 
question. It indicates that spring SSTs over the tropical Indian Ocean have a positive correlation with Meiyu precipitation according to the observational results. The correlation between averaged precipitation and pre-spring SSTs has large differences among atmospheric models. There are 9 out of 35 CMIP6/AMIP models that agree well with the observations, including ACCESS-ESM1-5, BCC-ESM1, CAMS-CSM1-0, CanESM5, CESM2-WACCM, EC-Earth3-CC, FGOALS-f3-L, IITM-ESM, MPIESM-HAM, MRI-ESM2-0, and TaiESM1. Figure S6 shows that the Top 20\% models in CMIP6/AMIP reflect more significant correlations between MAM SSTs in the Indian Ocean and averaged Meiyu precipitation.

We also selected warm IOBM years (1998, 2003, and 2010) and cold IOBM years $(1999,2000,2008,2011$, and 2013) to calculate the differences in circulations. As is shown in Figure 11 (b), (d), and (f), the Top 20\% of the CMIP6/AMIP models can simulate the closed Pacific high, but the location of the high center is relatively eastward. The Top 20\% models in CMIP6/AMIP models also perform better in the simulation of subtropical high, which is similar to the previous result.

\section{Summary and Conclusions}

In this study, we systematically assessed 35 CMIP6/AMIP models based on their performance in simulating the spatial pattern and interannual variability of Meiyu precipitation for the period 1998-2014. We selected the Top 20\% and Bottom 20\% models for Meiyu precipitation simulations, based on both the overall model ranking and IVS ranking. The possible reasons for the model biases among the two groups were also investigated.

For the Meiyu climatological features, 14 and 7 out of 35 models have reasonably simulated rainfall over K\&J and LYRB regions, respectively. CMIP6/AMIP models can thus reproduce the Meiyu precipitation better in the K\&J region than that in LYRB, which is also shown in the Taylor diagrams. Furthermore, most of the CMIP6/AMIP models fail to capture the characteristic of the Meiyu rainband with reduced precipitation in mid-July. For the Meiyu interannual variations, GFDL-CM4 and 
data, while CAMS-CSM1-0, CanESM5, CMCC-CM2-HR4, CMCC-CM2-SR5, four ECMWF models, INM-CM4-8, INM-CM5-0, MPI-ESM-1-2-HAM, MPI-ESM1-2-HR, and MRI-ESM2-0 show smaller variances.

We quantitively ranked the performance of the 35 models in simulating Meiyu precipitation both in climatology and interannual variation, and selected the Top $20 \%$ and Bottom 20\% in CMIP6/AMIP models. We also explored how the CMIP6/AMIP models reproduce the relationship between Meiyu precipitation, western Pacific subtropical high, and a subtropical jet. It is indicated that CESM2-WACCM-FV2, ECEarth3-CC, and MPI-ESM1-2-HAM agree well with the relationships based on observations and MERRA2. Among the 35 CMIP6/AMIP models, CESM2-WACCM, CESM2-WACCM- FV 2, CMCC-CM2-SR5, EC-Earth3-Veg, IPSL-CM6A-LR, MPIESM1-2-HAM, NorCPM1, and NorESM2-LM can realistically reproduce the EAP center located in the South China Sea, while most of the CMIP6/AMIP models successfully capture the EAP center in the mid to high latitudes.

Our evaluation was also done by examining how ENSO and IOBM influence Meiyu across atmospheric models as compared with observations. The more significant the positive correlations between averaged Meiyu precipitation and SSTs over both the eastern equatorial Pacific and the Indian Ocean are, the closer the atmospheric model simulations of Meiyu precipitation are to observations. Meanwhile, the Top $20 \%$ of models tend to simulate a more realistic western Pacific subtropical high than the Bottom 20\% of models in CMIP6/AMIP.

In conclusion, this study provides an assessment of CMIP6/AMIP models for simulating Meiyu precipitation. We lay a foundation for reducing errors and uncertainties of Meiyu precipitation projections and other climate events.

\section{Acknowledgments}

This work was supported by the National Natural Science Foundation of China (41875101), the National Key Research and Development Program of China (2017YFC1502303). We appreciate Prof. Jinming Ge for his suggestions on improving 
395 figures and all the data providers and the modeling groups for producing CMIP6 outputs. We also thank three anonymous reviewers for their constructive comments and kind suggestions on improving this paper.

Data availability The CMIP6/AMIP data can be downloaded from cmip6 Data Search | cmip6 | ESGF-CoG (llnl.gov). TRMM data is from OPeNDAP Hyrax: Contents of /TRMM_L3/TRMM_3B42_Daily.7/ (nasa.gov). The MERRA2 data set is available from GES DISC Search: Showing 1 - 25 of 99 datasets (nasa.gov).

\section{Declarations}

Funding The National Natural Science Foundation of China (41875101) and the National Key Research and Development Program of China (2017YFC1502303).

Conflicts of interest Not applicable.

Code availability Not applicable.

Authors' contributions Not applicable.

\section{References}

Chen, Y., Zhai, P., Liao, Z., \& Li, L. (2019). Persistent precipitation extremes in the Yangtze River Valley prolonged by opportune configuration among atmospheric teleconnections. Quarterly Journal of the Royal Meteorological Society, 145(723), 2603-2626. https://doi.org/10.1002/qj.3581

Chen, S., Yu, B., \& Chen, W. (2013). An analysis on the physical process of the influence of AO on ENSO. Climate Dynamics, 42(3-4), 973-989. doi:10.1007/s00382-012-1654-z

Chen, W., Jiang, Z., \& Li, L. (2011). Probabilistic Projections of Climate Change over China under the SRES A1B Scenario Using 28 AOGCMs. Journal of Climate, 24(17), 4741-4756. doi:10.1175/2011jcli4102.1

Chen, X., Dai, A., Wen, Z., \& Song, Y. (2021). Contributions of Arctic Sea-Ice Loss and East Siberian Atmospheric Blocking to 2020 Record-Breaking Meiyu-Baiu 
Rainfall. Geophysical Research Letters, 48(10), e2021GL092748. doi:https://doi.org/10.1029/2021GL092748

Choudhury, B. A., Rajesh, P. V., Zahan, Y., \& Goswami, B. N. (2021). Evolution of the Indian summer monsoon rainfall simulations from CMIP3 to CMIP6 models. Climate Dynamics. doi:10.1007/s00382-021-06023-0

Coppola, E., Raffaele, F., Giorgi, F., Giuliani, G., Xuejie, G., Ciarlo, J. M., . . Rechid, D. (2021). Climate hazard indices projections based on CORDEX-CORE, CMIP5 and CMIP6 ensemble. Climate Dynamics, 57(5), 1293-1383. doi:10.1007/s00382-021-05640-z

Darshana, P., Chowdary, J. S., Parekh, A., \& Gnanaseelan, C. (2022). Relationship between the Indo-western Pacific Ocean capacitor mode and Indian summer monsoon rainfall in CMIP6 models. Climate Dynamics. doi:10.1007/s00382021-06133-9

Ding, Y. (1992). Summer Monsoon Rainfalls in China. Journal of the Meteorological Society of Japan. Ser. II, 70(1B), 373-396. doi:10.2151/jmsj1965.70.1B_373

Ding, Y. (2004). SEASONAL MARCH OF THE EAST-ASIAN SUMMER MONSOON. In East Asian Monsoon (Vol. Volume 2, pp. 3-53): WORLD SCIENTIFIC.

Ding, Y., \& Chan, J. C. L. (2005). The East Asian summer monsoon: an overview. Meteorology and Atmospheric Physics, 89(1), 117-142. doi:10.1007/s00703005-0125-Z

Ding, Y., Liang, P., Liu, Y., \& Zhang, Y. (2020). Multiscale Variability of Meiyu and Its Prediction: A New Review. Journal of Geophysical Research: Atmospheres, 125(7). doi:10.1029/2019jd031496

Decker, M., Brunke, M. A., Wang, Z., Sakaguchi, K., Zeng, X., \& Bosilovich, M. G. (2012). Evaluation of the Reanalysis Products from GSFC, NCEP, and ECMWF Using Flux Tower Observations. Journal of Climate, 25(6), 1916-1944. doi:10.1175/jcli-d-11-00004.1

Dong, T., \& Dong, W. (2021). Evaluation of extreme precipitation over Asia in CMIP6 
models. Climate Dynamics. doi:10.1007/s00382-021-05773-1

Eyring, V., Bony, S., Meehl, G. A., Senior, C. A., Stevens, B., Stouffer, R. J., \& Taylor, K. E. (2016). Overview of the Coupled Model Intercomparison Project Phase 6 (CMIP6) experimental design and organization. Geoscientific Model Development, 9(5), 1937-1958. doi:10.5194/gmd-9-1937-2016

Fu, Y., Lin, Z., \& Wang, T. (2020). Simulated Relationship between Wintertime ENSO and East Asian Summer Rainfall: From CMIP3 to CMIP6. Advances in Atmospheric Sciences, 38(2), 221-236. doi:10.1007/s00376-020-0147-y

Gill, A. E. (1980). Some simple solutions for heat-induced tropical circulation. Quarterly Journal of the Royal Meteorological Society, 106(449), 447-462. doi:https://doi.org/10.1002/qj.49710644905

Hofstra, N., Haylock, M., New, M., Jones, P., \& Frei, C. (2008). Comparison of six methods for the interpolation of daily, European climate data. Journal of Geophysical Research, 113(D21). doi:10.1029/2008jd010100

Islam, M., \& Uyeda, H. (2007). Use of TRMM in determining the climatic characteristics of rainfall over Bangladesh. Remote Sensing of Environment, 108(3), 264-276. doi:10.1016/j.rse.2006.11.011

Jian, B., Li, J., Wang, G., Zhao, Y., Li, Y., Wang, J., . . Huang, J. (2021). Evaluation of the CMIP6 marine subtropical stratocumulus cloud albedo and its controlling factors. Atmospheric Chemistry and Physics, 21(12), 9809-9828. doi:10.5194/acp-21-9809-2021

Kosaka, Y., Xie, S.-P., \& Nakamura, H. (2011). Dynamics of Interannual Variability in Summer Precipitation over East Asia. Journal of Climate, 24(20), 5435-5453. doi:10.1175/2011JCLI4099.1

Lau, K. M., Kim, K. M., \& Yang, S. (2000). Dynamical and Boundary Forcing Characteristics of Regional Components of the Asian Summer Monsoon. Journal of Climate, 13(14), 2461-2482. doi:10.1175/15200442(2000)013<2461:DABFCO>2.0.CO;2

Li, G., Xie, S.-P., He, C., \& Chen, Z. (2017). Western Pacific emergent constraint lowers 
projected increase in Indian summer monsoon rainfall. Nature Climate Change, 7(10), 708-712. doi:10.1038/nclimate3387

Li, W., Jiang, Z., Xu, J., \& Li, L. (2015). Extreme Precipitation Indices over China in CMIP5 Models. Part I: Model Evaluation. Journal of Climate, 28(21), 86038619. doi:10.1175/jcli-d-15-0099.1

Matsumura, S., Horinouchi, T., Ose, T., \& Takayabu, Y. N. (2019). Jet-Precipitation Relation and Future Change of the Mei-Yu-Baiu Rainband and Subtropical Jet in CMIP5 Coupled GCM Simulations. Journal of Climate, 32(8), 2247-2259. doi:10.1175/jcli-d-18-0426.1

Na, Y., Lu, R., Fu, Q., \& Kodama, C. (2021). Precipitation Characteristics and Future Changes Over the Southern Slope of Tibetan Plateau Simulated by a HighResolution Global Nonhydrostatic Model. Journal of Geophysical Research: Atmospheres, 126(3). doi:10.1029/2020jd033630

Norris, J., Hall, A., Chen, D., Thackeray, C. W., \& Madakumbura, G. D. (2021). Assessing the Representation of Synoptic Variability Associated With California Extreme Precipitation in CMIP6 Models. Journal of Geophysical Research: Atmospheres, 126(6). doi:10.1029/2020jd033938

Ouma, Y. O., Owiti, T., Kipkorir, E., Kibiiy, J., \& Tateishi, R. (2012). Multitemporal comparative analysis of TRMM-3B42 satellite-estimated rainfall with surface gauge data at basin scales: daily, decadal and monthly evaluations. International Journal of Remote Sensing, 33(24), 7662-7684. doi:10.1080/01431161.2012.701347

Pan, X., Li, T., Sun, Y., \& Zhu, Z. (2021). Cause of Extreme Heavy and Persistent Rainfall over Yangtze River in Summer 2020. Advances in Atmospheric Sciences, 38(12), 1994-2009. doi:10.1007/s00376-021-0433-3

Qiao, S., Chen, D., Wang, B., Cheung, H. N., Liu, F., Cheng, J., . . Dong, W. (2021). The Longest 2020 Meiyu Season Over the Past 60 Years: Subseasonal Perspective and Its Predictions. Geophysical Research Letters, 48(9). doi:10.1029/2021g1093596 
Rajendran, K., Surendran, S., Varghese, S. J., \& Sathyanath, A. (2021). Simulation of Indian summer monsoon rainfall, interannual variability and teleconnections: evaluation of CMIP6 models. Climate Dynamics. doi:10.1007/s00382-02106027-w

Sampe, T., \& Xie, S.-P. (2010). Large-Scale Dynamics of the Meiyu-Baiu Rainband: Environmental Forcing by the Westerly Jet. Journal of Climate, 23(1), 113-134. doi:10.1175/2009JCLI3128.1

Sibson, R. (1981), A brief description of natural neighbour interpolation, in Interpreting Multivariate Data, edited by V. Barnett, pp. 21 - 36, John Wiley and Sons, Chichester, UK.

Simpson, J., Adler, R. F., \& North, G. R. (1988). A Proposed Tropical Rainfall Measuring Mission (TRMM) Satellite. Bulletin of the American Meteorological Society, 69(3), 278-295. doi:10.1175/15200477(1988)069<0278:APTRMM>2.0.CO;2

Stouffer, R. J., Eyring, V., Meehl, G. A., Bony, S., Senior, C., Stevens, B., \& Taylor, K. E. (2017). CMIP5 Scientific Gaps and Recommendations for CMIP6. Bulletin of the American Meteorological Society, 98(1), 95-105. doi:10.1175/BAMS-D$15-00013.1$

Takaya, Y., Ishikawa, I., Kobayashi, C., Endo, H., \& Ose, T. (2020). Enhanced MeiyuBaiu Rainfall in Early Summer 2020: Aftermath of the 2019 Super IOD Event. Geophysical Research Letters, 47(22). doi:10.1029/2020g1090671

Tang, Q., Zhang, X., \& Francis, J. A. (2014). Extreme summer weather in northern midlatitudes linked to a vanishing cryosphere. Nature Climate Change, 4(1), 45-50. doi:10.1038/nclimate2065

Tao, S. Y. (1987). A review of recent research on the East Asian summer monsoon in China. Monsoon Meteorology, 60-92. Retrieved from https://ci.nii.ac.jp/naid/10012388648/en/

Taylor, K. E. (2001). Summarizing multiple aspects of model performance in a single diagram. Journal of Geophysical Research: Atmospheres, 106(D7), 7183-7192. 
doi:10.1029/2000jd900719

Tong, M., Zheng, Z., \& Fu, Q. (2021). Characteristics of Meiyu Seen From Multiple Observational Analyses and Reanalyses. Earth and Space Science, 8(4). doi:10.1029/2021ea001647

Vimont, D. J., Battisti, D. S., \& Hirst, A. C. (2003). The Seasonal Footprinting Mechanism in the CSIRO General Circulation Models. Journal of Climate, 16(16), 2653-2667. doi:10.1175/15200442(2003)016<2653:TSFMIT>2.0.CO;2

Wang, C., Liang, X.-Z., \& Samel, A. N. (2011). AMIP GCM Simulations of Precipitation Variability over the Yangtze River Valley. Journal of Climate, 24(8), 2116-2133. doi:10.1175/2011jcli3631.1

Wang, J., Liu, Y., Ding, Y., \& Wu, Z. (2021). Towards influence of Arabian Sea SST anomalies on the withdrawal date of Meiyu over the Yangtze-Huaihe River basin. Atmospheric Research, 249, 105340. doi:https://doi.org/10.1016/j.atmosres.2020.105340

555 Wang, W., Chakraborty, T. C., Xiao, W., \& Lee, X. (2021). Ocean surface energy balance allows a constraint on the sensitivity of precipitation to global warming. Nat Commun, 12(1), 2115. doi:10.1038/s41467-021-22406-7

Wang, X., Zhu, J., Chang, C.-H., Johnson, N. C., Liu, H., Li, Y., . . Li, X. (2021). Underestimated responses of Walker circulation to ENSO-related SST anomaly in atmospheric and coupled models. Geoscience Letters, $8(1)$. doi:10.1186/s40562-021-00186-8

Wang, Z., Han, L., Zheng, J., Ding, R., Li, J., Hou, Z., \& Chao, J. (2021). Evaluation of the Performance of CMIP5 and CMIP6 Models in Simulating the Victoria Mode-El Niño Relationship. Journal of Climate, 34(18), 7625-7644. doi:10.1175/jcli-d-20-0927.1

Wolff, D. B., Marks, D. A., Amitai, E., Silberstein, D. S., Fisher, B. L., Tokay, A., . . Pippitt, J. L. (2005). Ground Validation for the Tropical Rainfall Measuring Mission (TRMM). Journal of Atmospheric and Oceanic Technology, 22(4), 
365-380. doi:10.1175/JTECH1700.1

Wolff, D. B., Nelkin, E. J., Bolvin, D. T., Huffman, G. J., Adler, R. F., Gu, G., . . . Stocker, E. F. (2007). The TRMM Multisatellite Precipitation Analysis (TMPA): Quasi-Global, Multiyear, Combined-Sensor Precipitation Estimates at Fine Scales. Journal of Hydrometeorology, 8(1), 38-55. doi:10.1175/jhm560.1

Wu, B., Chen, X., \& Zhou, T. (2019). Frontier issues on climate change science for supporting Future Earth. Chinese Science Bulletin, 64(19), 1967-1974. doi:10.1360/n972018-00818

Xie, S.-P., Kosaka, Y., Du, Y., Hu, K., Chowdary, J. S., \& Huang, G. (2016). Indowestern Pacific ocean capacitor and coherent climate anomalies in post-ENSO summer: A review. Advances in Atmospheric Sciences, 33(4), 411-432. doi:10.1007/s00376-015-5192-6

Xie, S.-P., \& Philander, S. G. H. (1994). A coupled ocean-atmosphere model of relevance to the ITCZ in the eastern Pacific. Tellus A: Dynamic Meteorology and Oceanography, 46(4), 340-350. doi:10.3402/tellusa.v46i4.15484

Xu, H., Goldsmith, Y., Lan, J., Tan, L., Wang, X., Zhou, X., . . . Liu, C. (2020). Juxtaposition of Western Pacific Subtropical High on Asian Summer Monsoon Shapes Subtropical East Asian Precipitation. Geophysical Research Letters, 47(3). doi:10.1029/2019g1084705

Yang, H. X., Xiao, T. G., \& Jin, R. H. (2018). Analysis of Time and Space and Circulation Characteristics of EAP Teleconnection Patterns in the Northern Hemisphere in Summer. Journal of Chengdu University of Information Technology.

Zhao, H. G., Zhang, X. G., \& Ding, Y. H. (1989). EL NINO AND THE ANOMALOUS CLIMATE IN CHINA. Acta Meteorologica Sinica.

Zhou, S., Huang, G., \& Huang, P. (2020). Inter-model Spread of the Changes in the East Asian Summer Monsoon System in CMIP5/6 Models. Journal of Geophysical Research: Atmospheres, 125(24). doi:10.1029/2020jd033016

Zhou, Z., Xie, S. P., \& Zhang, R. (2021). Historic Yangtze flooding of 2020 tied to 
extreme Indian Ocean conditions. Proc Natl Acad Sci U S A, 118(12). doi:10.1073/pnas.2022255118

600

\section{Figure captions}

Figure 1 Spatial patterns of TRMM daily precipitation (a) and variance (b) averaged during the Meiyu season for 1998-2014. The Meiyu area is highlighted by the white dashed-line box, which is $28^{\circ} \mathrm{N}-36^{\circ} \mathrm{N}, 110^{\circ} \mathrm{E}-140^{\circ} \mathrm{E}$.

Figure 2 Same as Fig.1(a) but for 35 individual CMIP6/AMIP models (each model is averaged from all its realizations).

Figure 3 Time-latitude evolution of Meiyu rainband from $28^{\circ} \mathrm{N}-36^{\circ} \mathrm{N}$ during the Meiyu season from June 1 to July 31 , averaged over $110^{\circ} \mathrm{E}$ to $140^{\circ} \mathrm{E}$ and for 1998 2014 from TRMM and 35 CMIP6/AMIP models (each model is averaged from all realizations).

Figure 4 Taylor diagrams for daily precipitation during the Meiyu season for 1998-2014 for 35 individual CMIP6/AMIP models as compared with the TRMM observations over the (a) K\&J, (b) LYRB, and (c) the entire Meiyu area.

Figure 5 Same as Fig.1(b) but for 35 individual CMIP6/AMIP models (each model is averaged from all its realizations).

Figure 6 (a) Time series of Meiyu precipitation anomalies among 35 CMIP6/AMIP models and TRMM. (b) Interannual Variability Scores (IVS) among 35 CMIP6/AMIP models.

Figure 7 Correlation between the Meiyu precipitation averaged over the Meiyu area and 500-hPa geopotential height for the TRMM\&MERRA2 and 35 CMIP6/AMIP models (each model is averaged from all realizations).

Figure 8 Same as Fig.7 but between the Meiyu precipitation averaged over the Meiyu area and 200-hPa zonal wind (u).

Figure 9 The same as Fig.7 but between the Meiyu precipitation averaged over the Meiyu area and the pre-winter Hadley-OI SST. The precipitation is from TRMM and 35 CMIP6/AMIP models. 
Figure 10 The same as Fig.9 but between the Meiyu precipitation averaged over the Meiyu area and the pre-spring Hadley-OI SST.

Figure 11 Differences in circulation fields between strong El Niño years and strong La 630 Niña years ((a), (c), and (e)), and differences in circulation fields between warm IOBM years and cold IOBM years ((b), (d), and (f)) during the Meiyu season. The geopotential heights are at 500-hPa level, and contour intervals are $2 \mathrm{~m}$. The wind is at $850-\mathrm{hPa}$ level. 


\section{Figures}
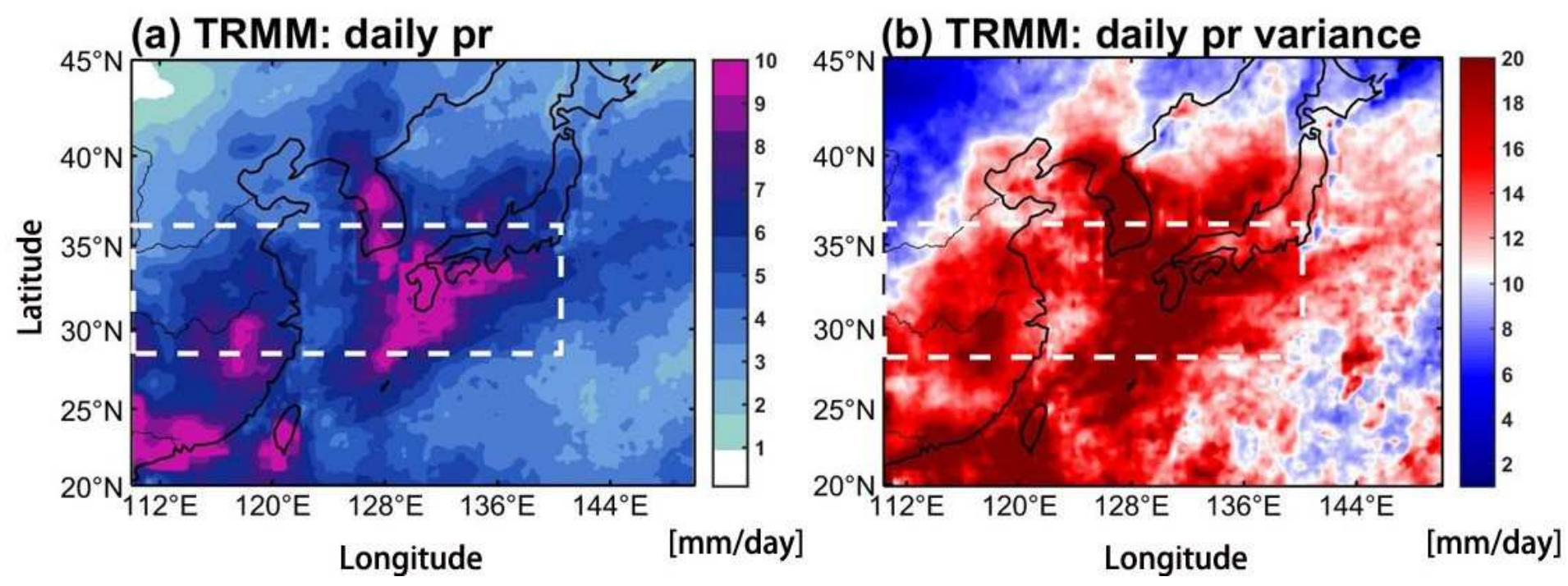

Figure 1

Spatial patterns of TRMM daily precipitation (a) and variance (b) averaged during the Meiyu season for $1998-2014$. The Meiyu area is highlighted by the white dashed-line box, which is $28^{\circ} \mathrm{N}-36^{\circ} \mathrm{N}, 110^{\circ} \mathrm{E}$ $-140^{\circ} \mathrm{E}$. 

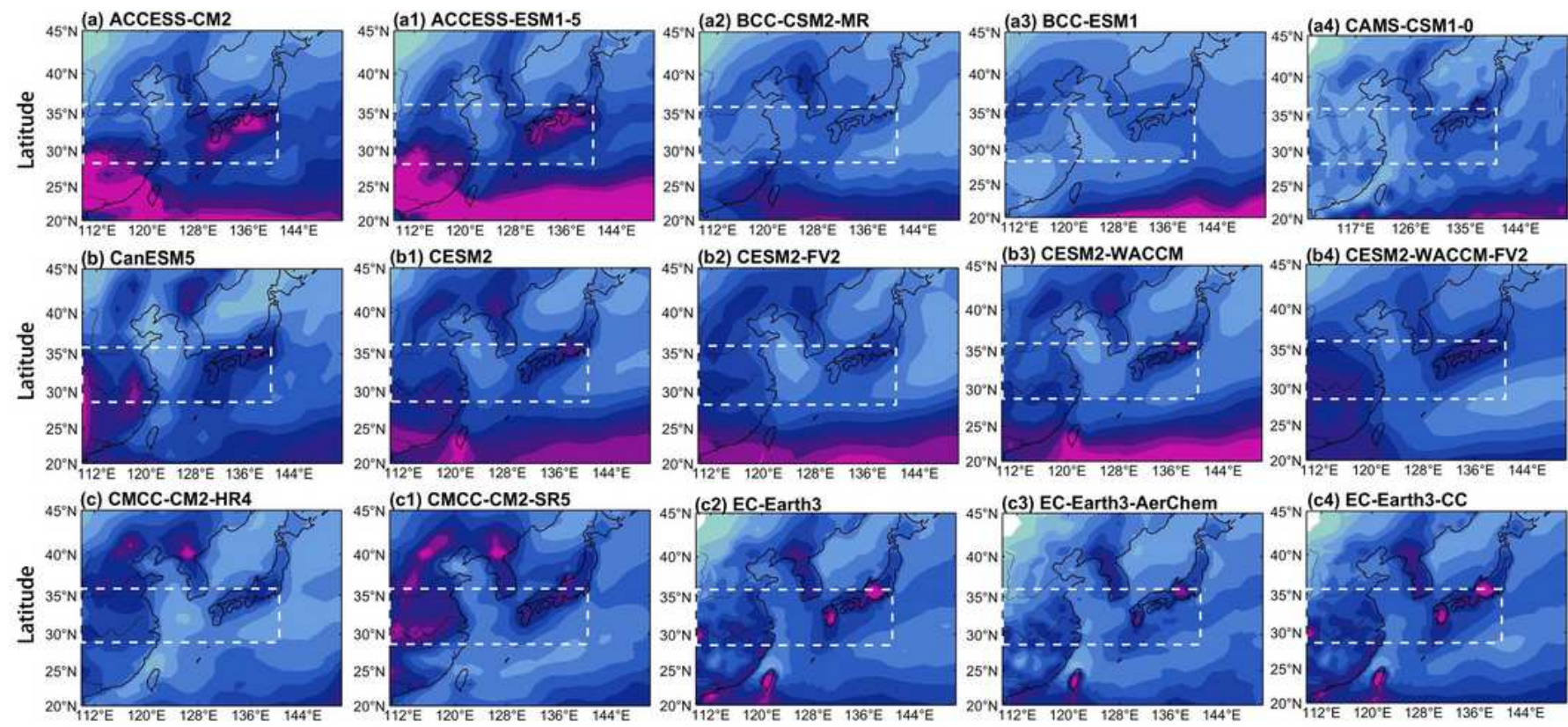

(c4) EC-Earth3-CC
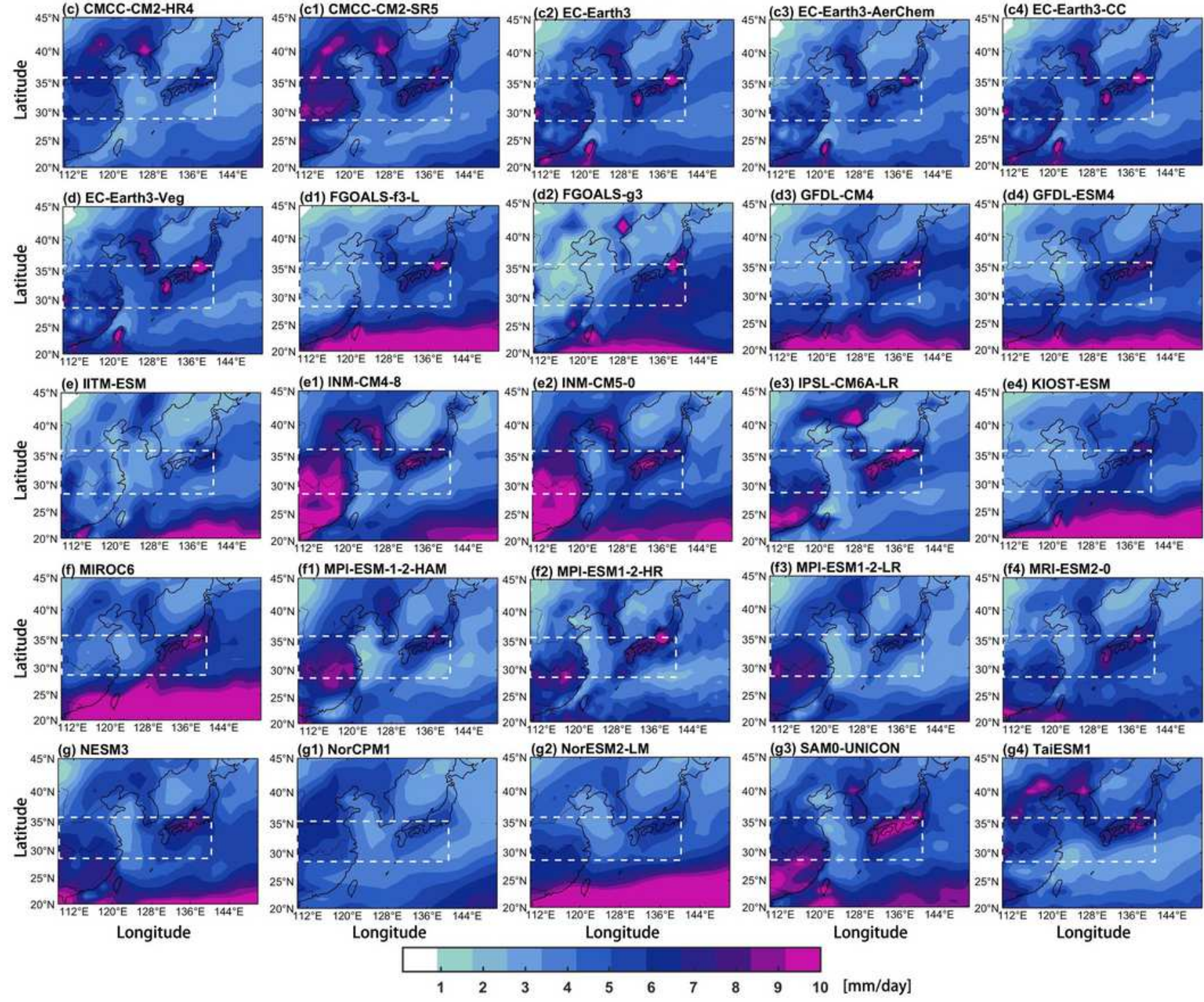

Longitude

Longitude

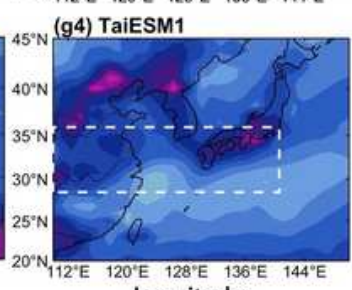

$\begin{array}{llllllllll}2 & 3 & 4 & 5 & 6 & 7 & 8 & 9 & 10 & \text { [mm/day }]\end{array}$

\section{Figure 2}

Same as Fig.1(a) but for 35 individual CMIP6/AMIP models (each model is averaged from all its realizations). 
Time-latitude evolution of Meiyu rainband from $28^{\circ} \mathrm{N}-36^{\circ} \mathrm{N}$ during the Meiyu season from June 1 to July 31 , averaged over $110^{\circ} \mathrm{E}$ to $140^{\circ} \mathrm{E}$ and for $1998-2014$ from TRMM and 35 CMIP6/AMIP models (each model is averaged from all realizations).

(a) K\&J

(b) LYRB
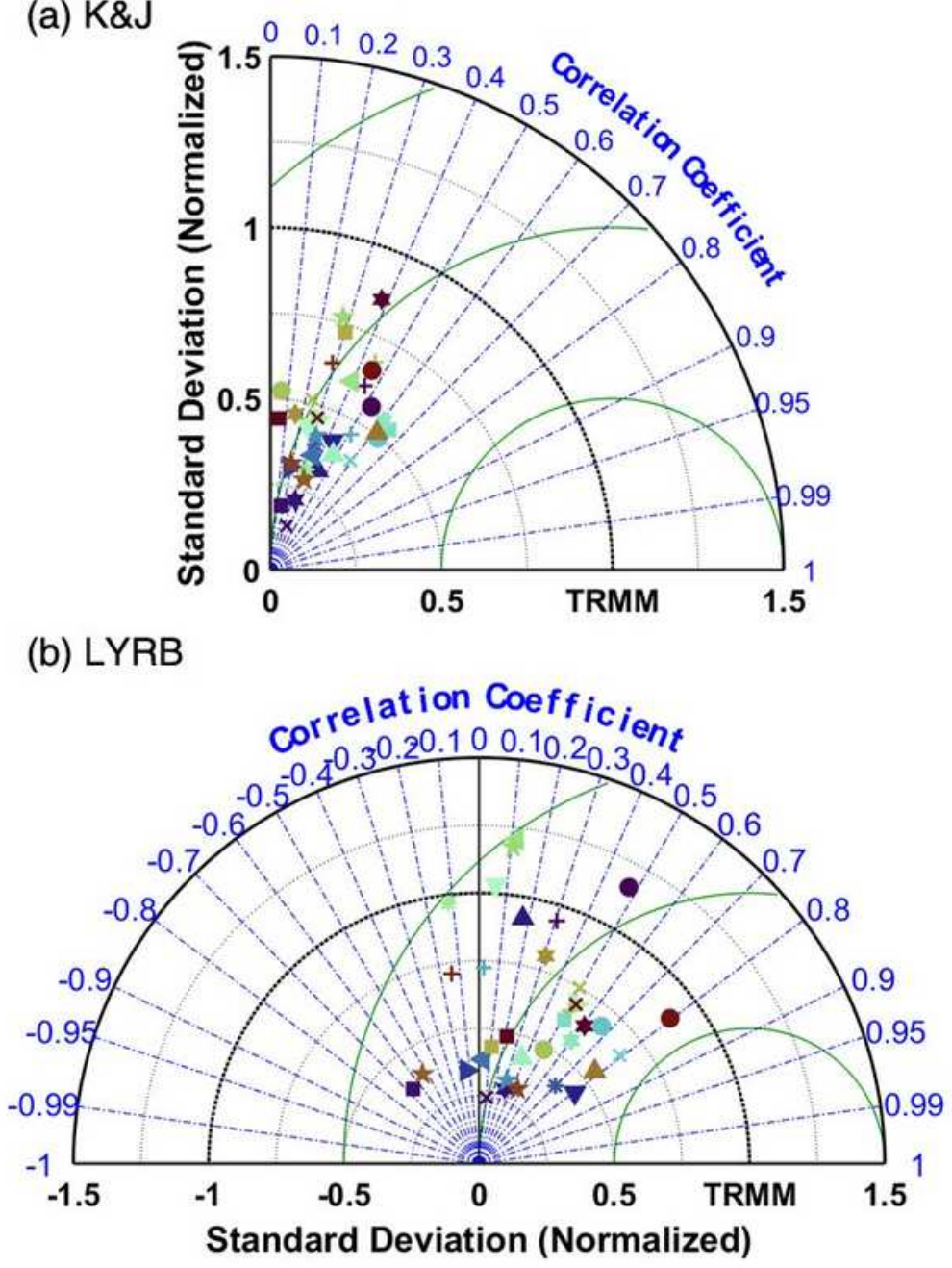

(c) Meiyu Area

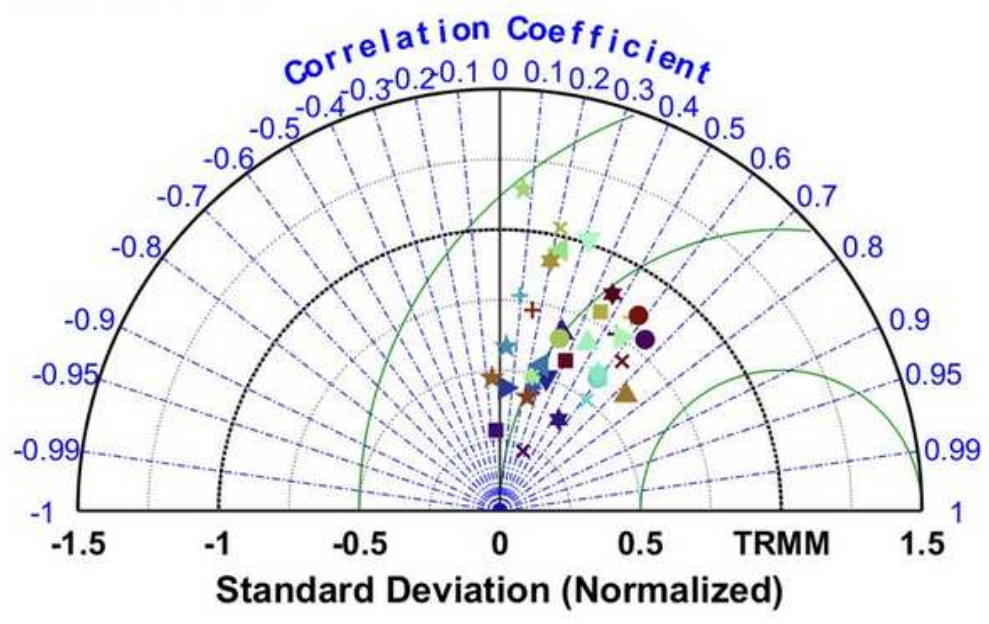

+ ACCESS-ESM1-5

- ACCESS-CM2

$\times$ BCC-CSM2-MR

- BCC-ESM1

* CAMS-CSM1-0

$\triangle$ CanESM5

$\nabla$ CESM2

$\checkmark$ CESM2-FV2

* CESM2-WACCM

$\triangle$ CESM2-WACCM-FV2

$\star$ CMCC-CM2-HR4

+ CMCC-CM2-SR5

- EC-Earth3

$\times$ EC-Earth3-AerChem

- EC-Earth3-CC

* EC-Earth3-Veg

FGOALS-f3-L

FGOALS-g3

GFDL_CM4

IITM-ESM

4 INM-CM5-0

* INM-CM-4-8

+ IPSL-CM6A-LR

- KIOST-ESM

$\times$ MPI-ESM-HAM

MIROC6

* MPI-ESM1-LR

$\triangle$ MRI-ESM2-0

$\star$ NorCPM1

$\star$ NorESM2-LM

+ TaiESM1

- MPI-ESM1-2-HR

$\times$ GFDL-ESM4

- NESM3

* SAMO-UNICON

Figure 4 
Taylor diagrams for daily precipitation during the Meiyu season for 1998-2014 for 35 individual CMIP6/AMIP models as compared with the TRMM observations over the (a) K\&J, (b) LYRB, and (c) the entire Meiyu area.
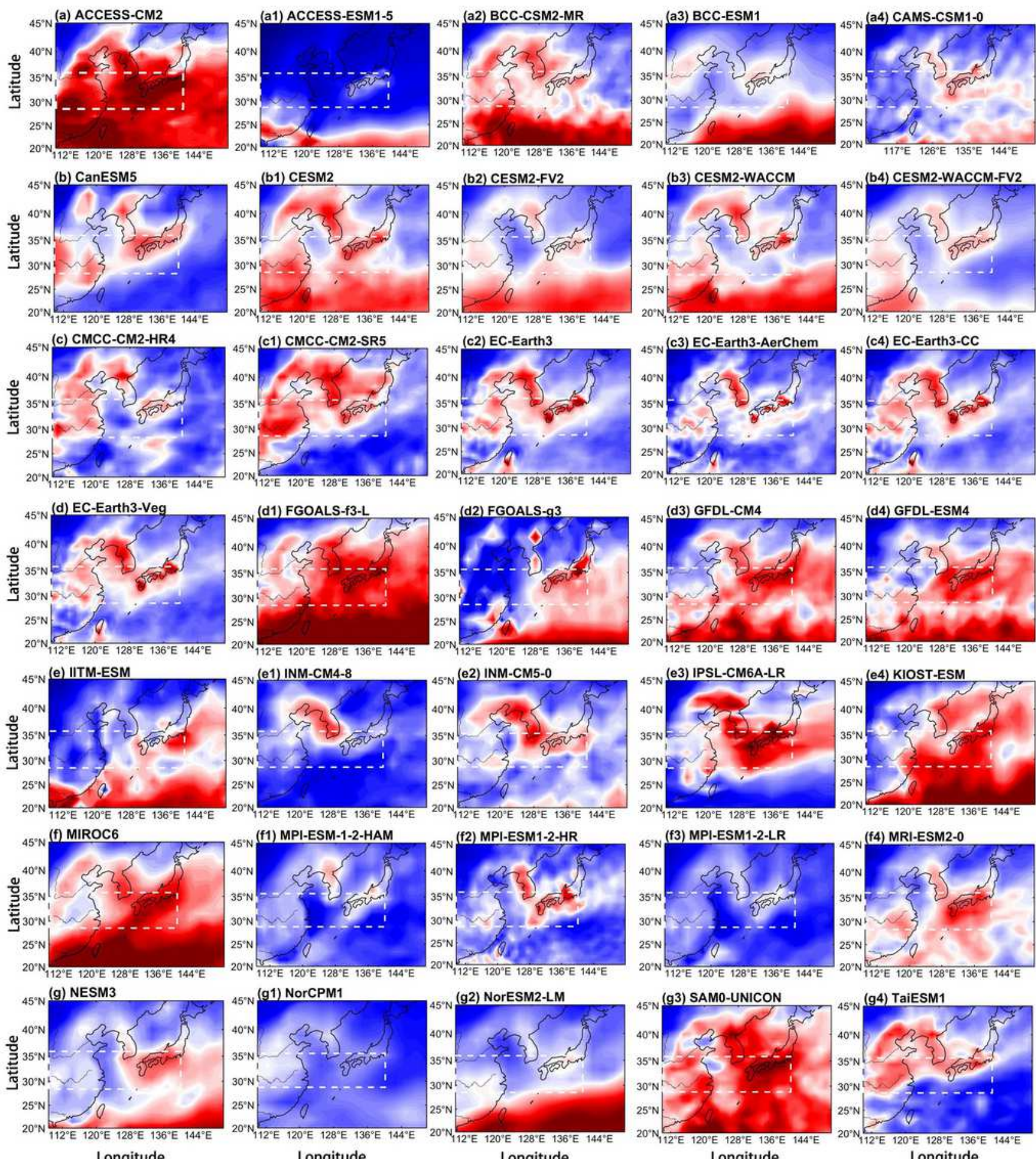

Longitude Longitude Longitude Longitude

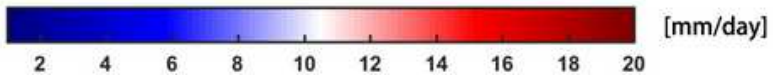

\section{Figure 5}


Same as Fig.1(b) but for 35 individual CMIP6/AMIP models (each model is averaged from all its realizations).

(a) Time series of precipitation anomalies
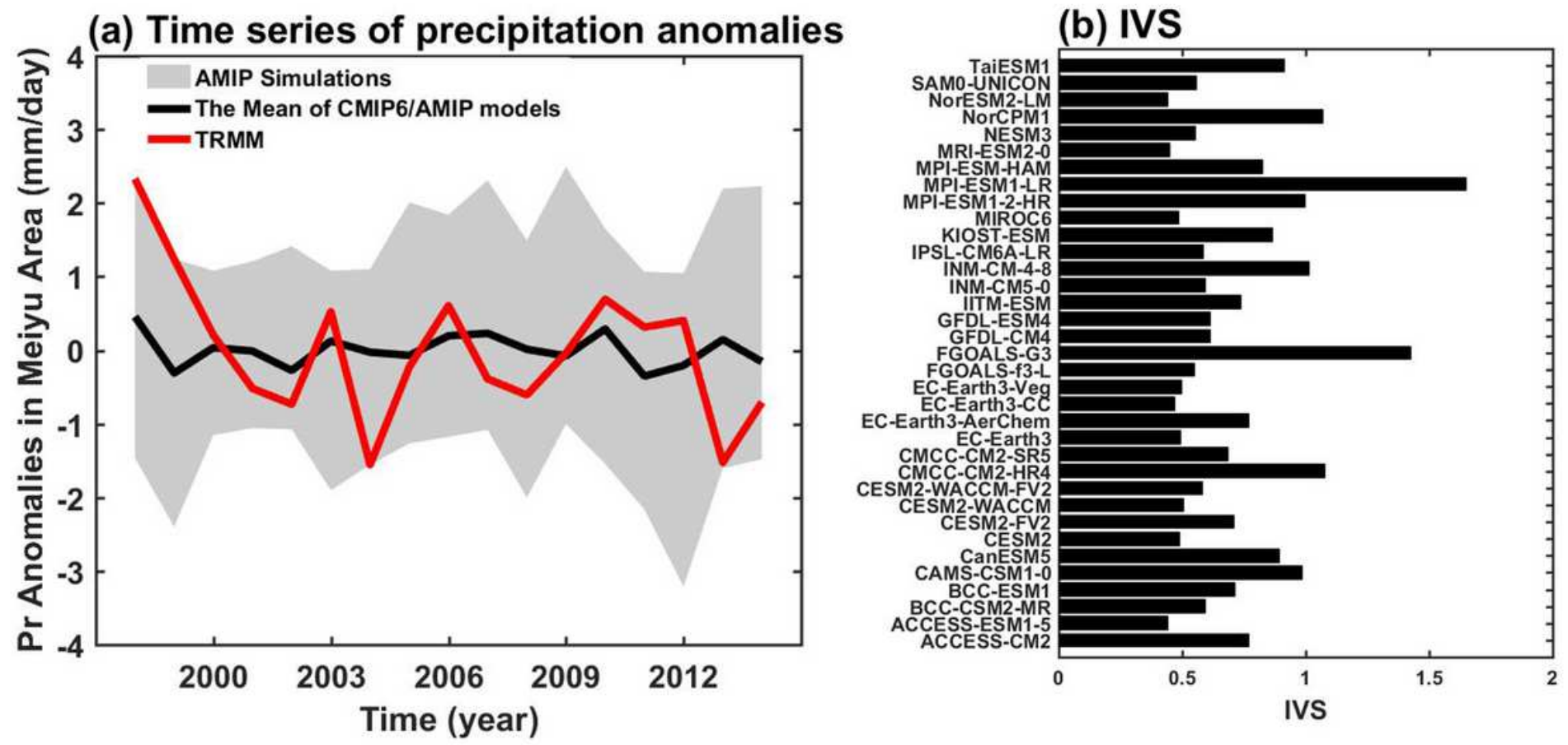

Figure 6

(a) Time series of Meiyu precipitation anomalies among 35 CMIP6/AMIP models and TRMM. (b) Interannual Variability Scores (IVS) among 35 CMIP6/AMIP models. 

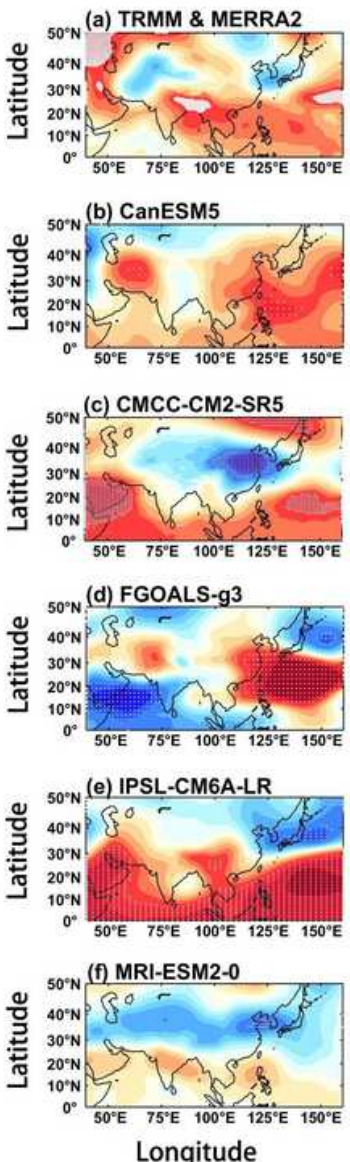

Longitude

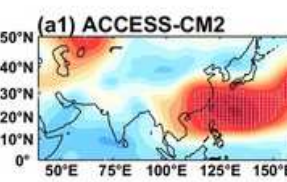

(a2) ACCESS-ESM1-5

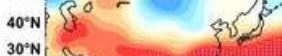

${ }_{20}^{30^{\circ} \mathrm{N}}$

${ }^{20} 0^{\circ} \mathrm{N}$
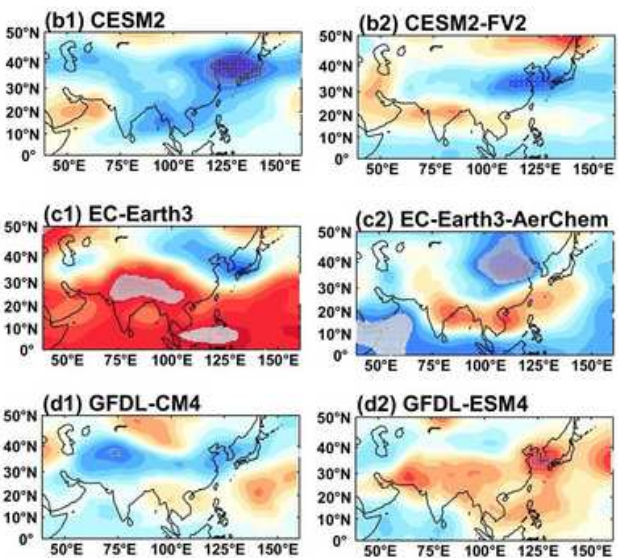

${ }^{50} \mathrm{~N}$ (d2) GFDL-ESM4
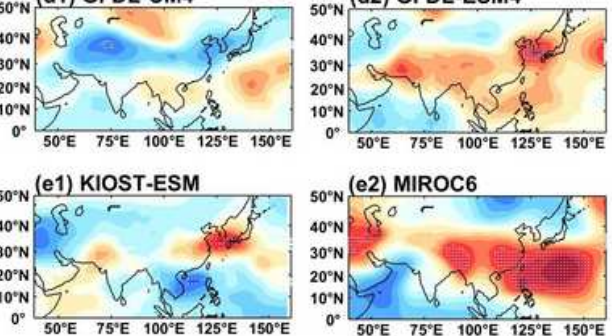

${ }_{50}^{\circ}$ (e2) MIROC6
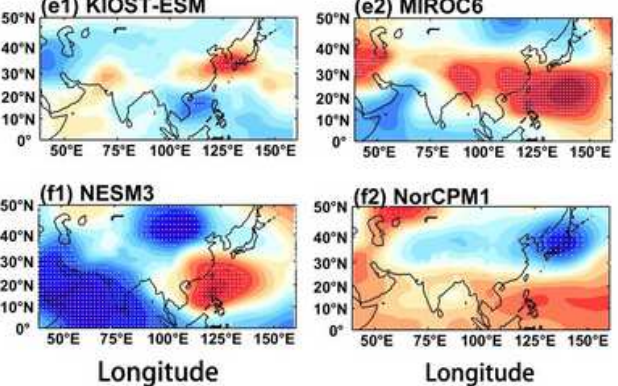

Longitude
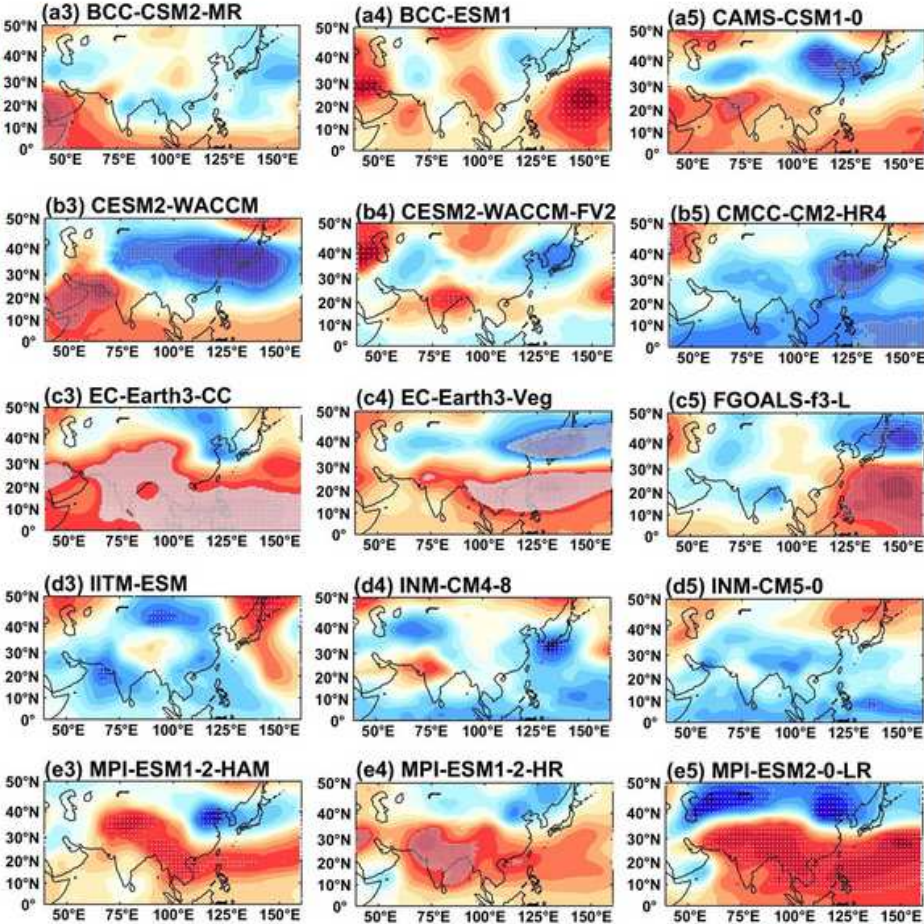

${ }_{50}^{\circ} \mathrm{N}$ (e4) MPI-ESM1-2-HR

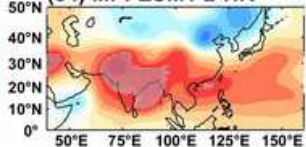

(e5) MPI-ESM2-0-LR
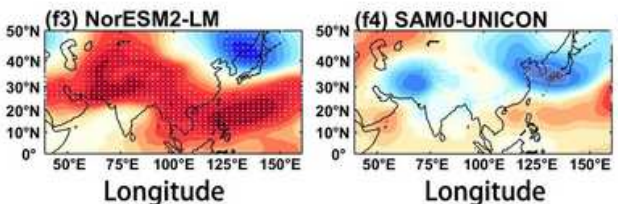
Longitude

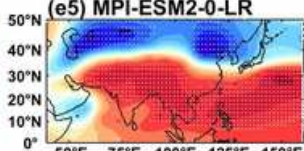

(f5) TaiESM1

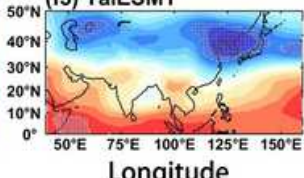

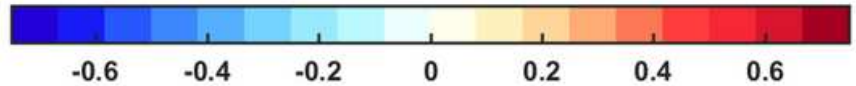

Figure 7

Correlation between the Meiyu precipitation averaged over the Meiyu area and 500-hPa geopotential height for the TRMM\&MERRA2 and 35 CMIP6/AMIP models (each model is averaged from all realizations). 
$50^{\circ} \mathrm{N}$ (a) TRMM \& MERRA2
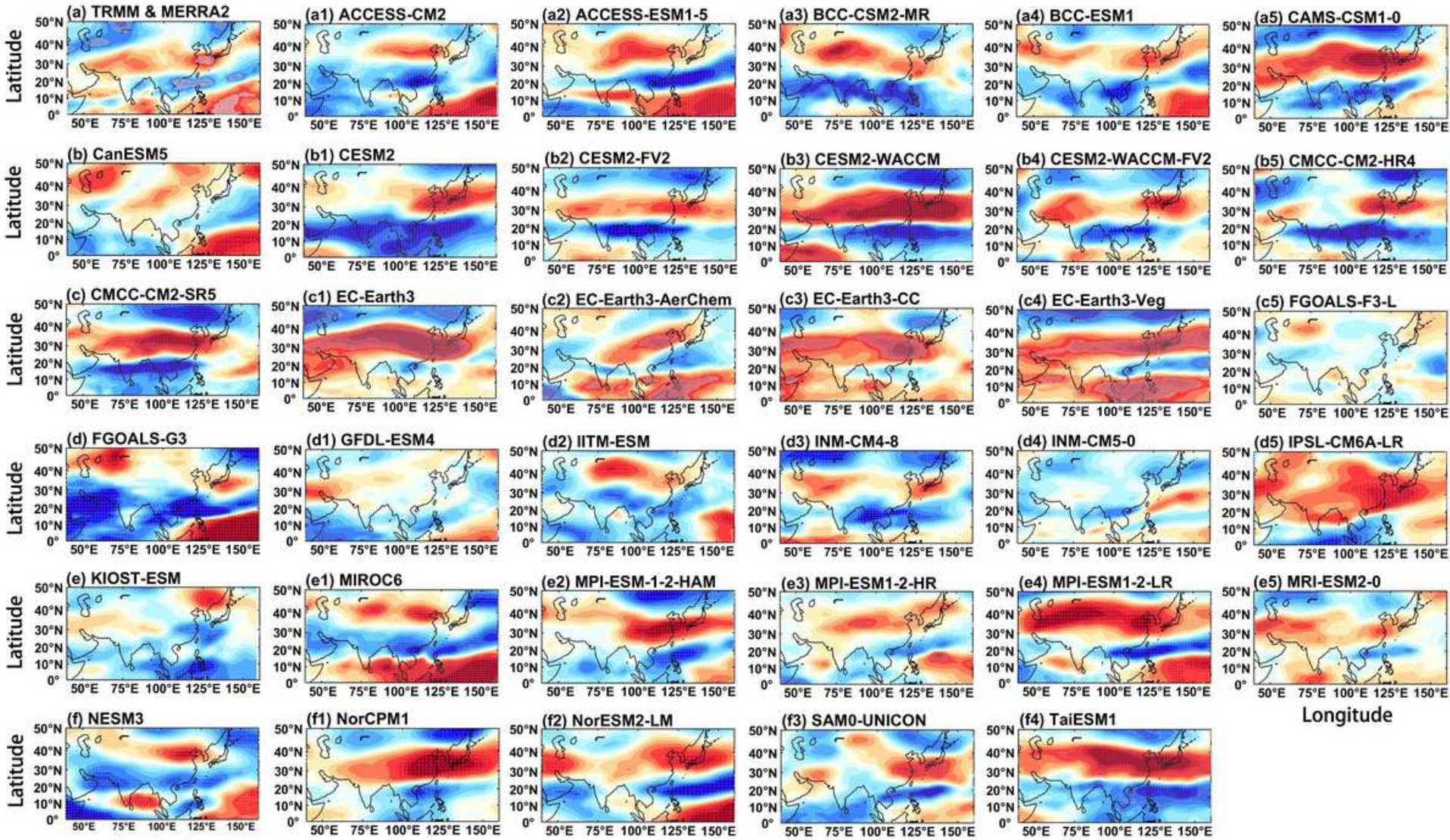

Longitude

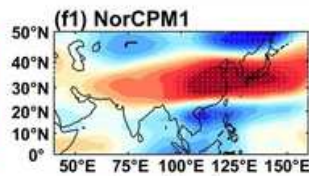

Longitude
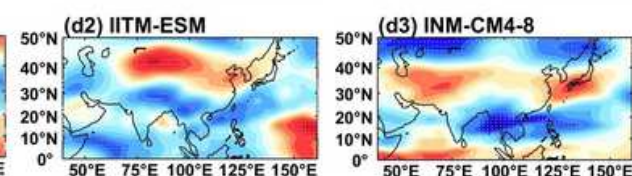

$50^{\circ} \mathrm{N}$ (e2) MPI-ESM-1-2-HAM

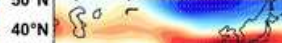

$30^{\circ} \mathrm{N}$

$20^{\circ} \mathrm{N}$

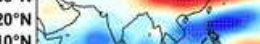

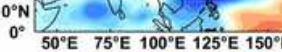

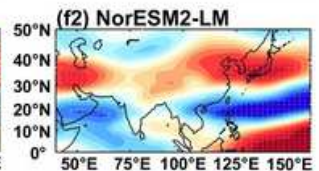

Longitude (e3) MPI-ESM1-2-HR

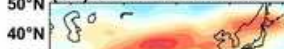

$30^{\circ} \mathrm{N}$

$20^{\circ} \mathrm{N}$

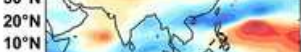

$0^{\circ} 50^{\circ} \mathrm{E} 75^{\circ} \mathrm{E} 100^{\circ} \mathrm{E} 125^{\circ} \mathrm{E} 150^{\circ} \mathrm{E}$
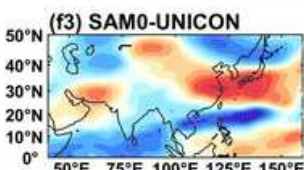

Longitude

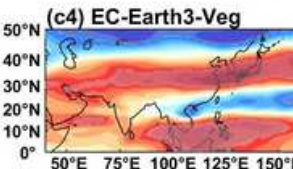

$0^{\circ} 5^{\circ} \mathrm{E} \quad 75^{\circ} \mathrm{E} \quad 100^{\circ} \mathrm{E} \quad 125^{\circ} \mathrm{E} \quad 150^{\circ}$

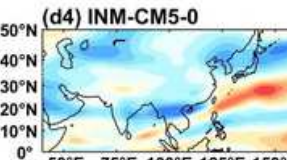

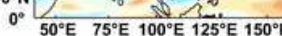

(e4) MPI-ESM1-2-LR
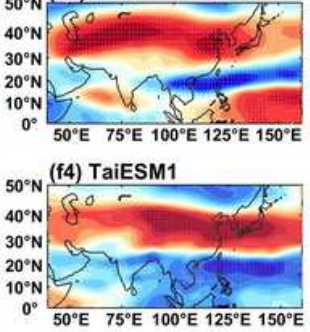
Longitude

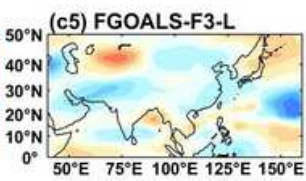

50\% (d5) IPSL-CM6A-LR

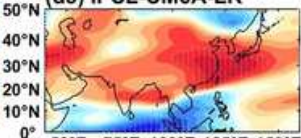

$0^{\circ} \quad 0^{\circ} \mathrm{E} \quad 75^{\circ} \mathrm{E} \quad 100^{\circ} \mathrm{E} \quad 125^{\circ} \mathrm{E} \quad 150^{\circ} \mathrm{E}$ (e5) MRI-ESM2-0

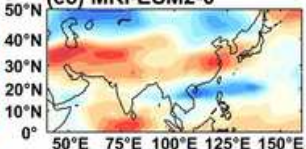

Longitude

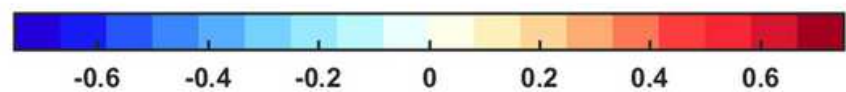

\section{Figure 8}

Same as Fig.7 but between the Meiyu precipitation averaged over the Meiyu area and 200-hPa zonal wind (u). 
(a) TRMM \& Hadley OI SST (a1) ACCESS-CM2

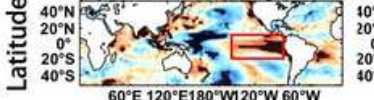

(b) CanESM5

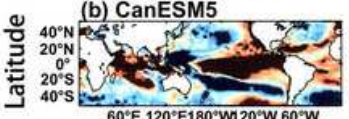

(c) CMCC-CM2-SR5

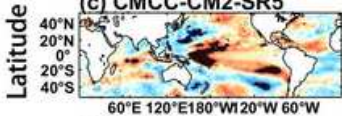

(d) FGOALS-G3
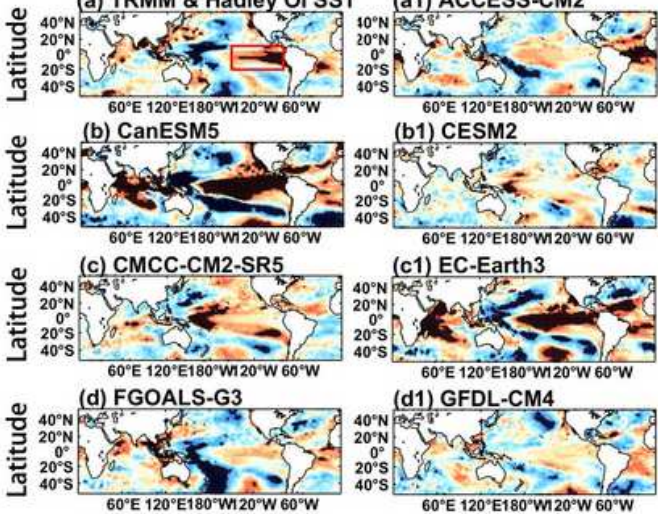

(b1) CESM2

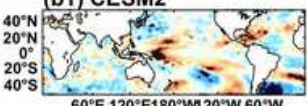

(c1) EC-Earth3

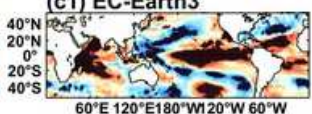

(d1) GFDL-CM4

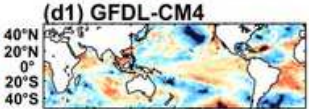

(e) IPSL-CM6A-LR

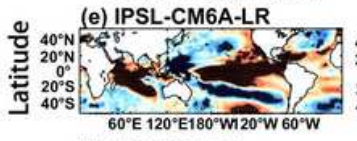

(e1) KIOST-ESM

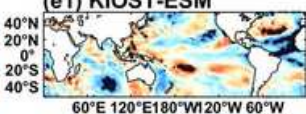

(f1) NESM3

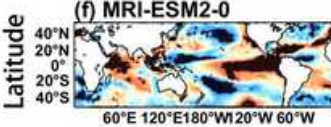

Longitude

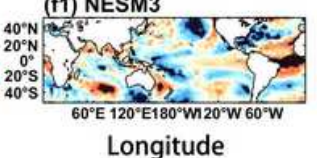

(a2) ACCESS-ESM1-5

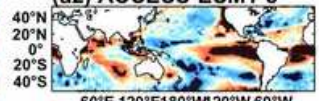

(b2) CESM2-FV2

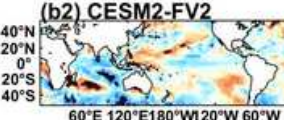

(c2) EC-Earth3-AerChem

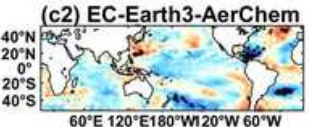

(d2) GFDL-ESM4

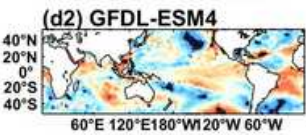

(e2) MIROC6

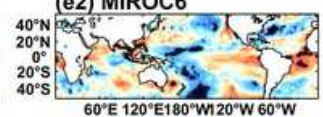

(f2) NorCPM1

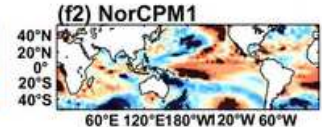

Longitude (a3) BCC-CSM2-MR

(b3) CESM2-WACCM

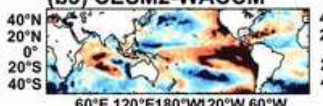

3) $E C$ - arth 3 -CC

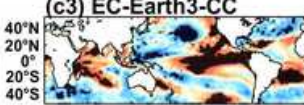

C0. $120^{\circ} \mathrm{E} 180^{\circ} \mathrm{W} 20^{\circ} \mathrm{W} 60^{\circ} \mathrm{W}$

(d3) IITM-ESM

o.

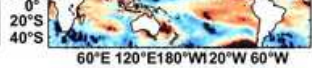

(e3) MPI-ESM-HAM

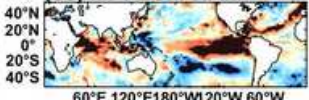

(f3) NorESM2-LM

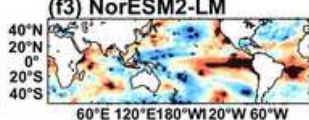

Longitude
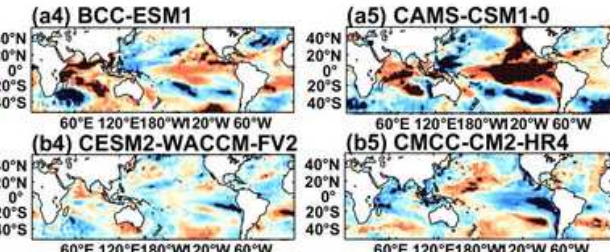

(c4) EC-Earth3-Veg

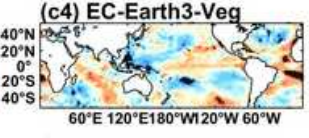

(d4) INM-CM-4-8

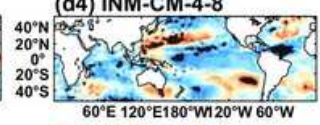

(e4) MPI-ESM1-2-HR

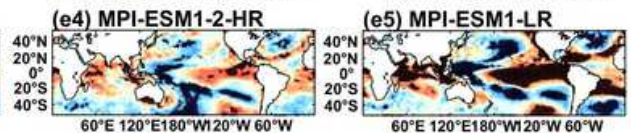

(f5) TaiESM1 (d5) INM-CM5-0 (c5) FGOALS-f3-L

(a5) CAMS-CSM1-0

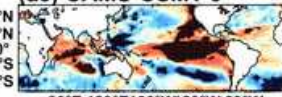

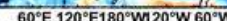

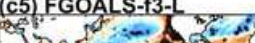

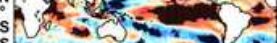

\begin{tabular}{ccccccc}
\hline &, & , & , & , & \\
-0.6 & -0.4 & -0.2 & 0 & 0.2 & 0.4 & 0.6
\end{tabular}

(f4) SAMO-UNICON

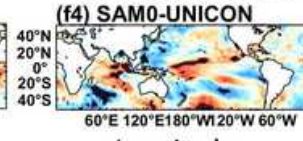

Longitude

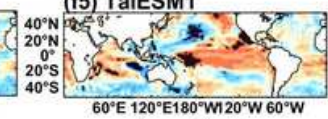

Longitude

Figure 9

The same as Fig.7 but between the Meiyu precipitation averaged over the Meiyu area and the pre-winter Hadley-OI SST. The precipitation is from TRMM and 35 CMIP6/AMIP models.

(a) TRMM \& Hadley OI SST, (a1) ACCESS-CM2

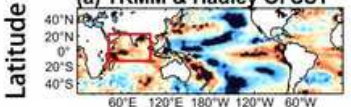

(b) CanESM5

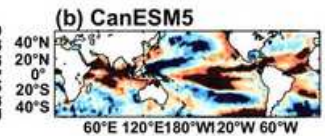

(c) CMCC-CM2-SR5
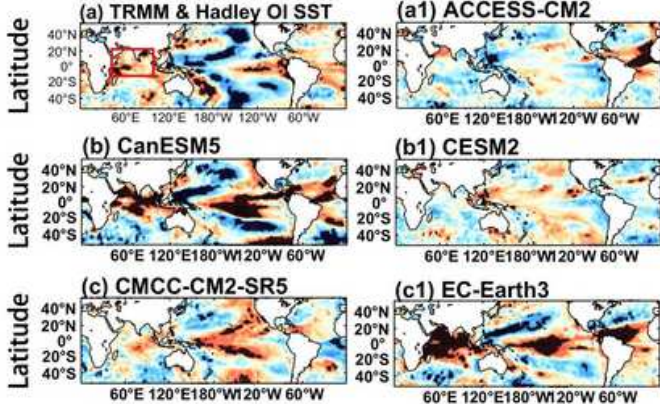

(b1) CESM2

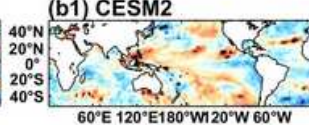

(c1) EC-Earth3

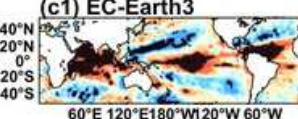

(d) FGOALS-G3

(d1) GFDL-CM4

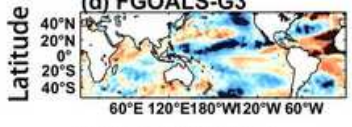

(e) IPSL-CM6A-LR

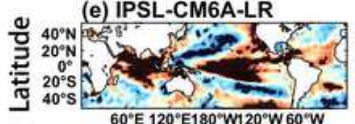

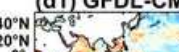

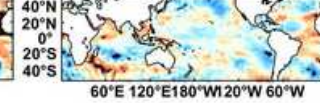

(e1) KIOST-ESM

$\begin{array}{lll}\text { (f) MRI-ESM2-0 (f1) NESM3 } & \end{array}$

$120^{\circ} \mathrm{E} 180^{\circ} \mathrm{W} 120^{\circ} \mathrm{W} 60^{\circ} \mathrm{W}$

夏 ${ }^{20^{\circ} 0^{\circ} \mathrm{S}} \frac{\mathrm{S}}{60^{\circ} \mathrm{E} 120^{\circ} \mathrm{E} 180^{\circ} \mathrm{W} 120^{\circ} \mathrm{W} 60^{\circ} \mathrm{W}}=$ Longitude

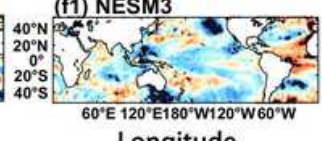

Longitude (a2) ACCESS-ESM1-5

(a3) BCC-CSM2-MR

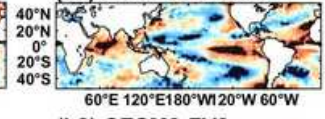

(b2) CESM2-FV2

(a4) BCC-ESM1

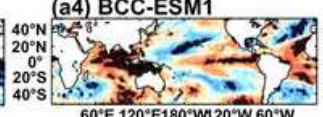

(a5) CAMS-CSM1-0

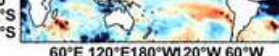

(b3) CESM2-WACCM

(b4) CESM2-WACCM-FV2 (b5) CMCC-CM2-HR4

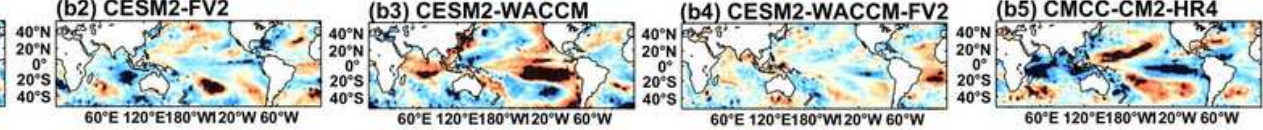

(c2) EC-Earth3-AerChem (c3) EC-Earth3-CC

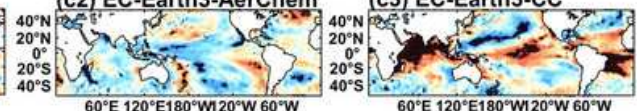

(c4) EC-Earth3-Veg

(d3) IITM-ESM

(d2) GFDL-ESM4

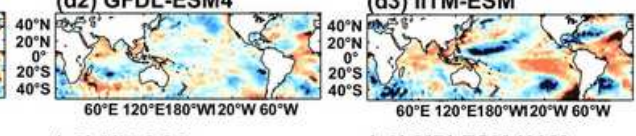

(e2) MIROC6

(e3) MPI-ESM-HAM

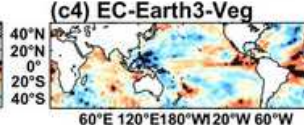

(c5) FGOALS-f3-L

(d4) INM-CM-4-8

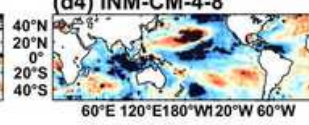

(d5) INM-CM5-0
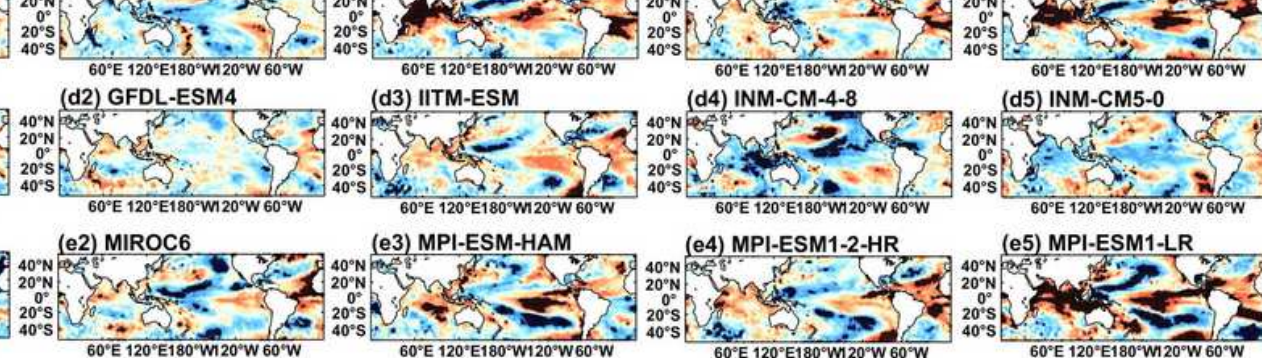

(e4) MPI-ESM1-2-HR

$\begin{array}{lll}\text { (f2) NorCPM1 } & \text { (f3) NorESM2-LM } \\ \text { (f4) SAMO-UNICON }\end{array}$

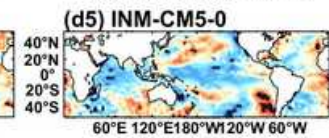

(e5) MPI-ESM1-LR
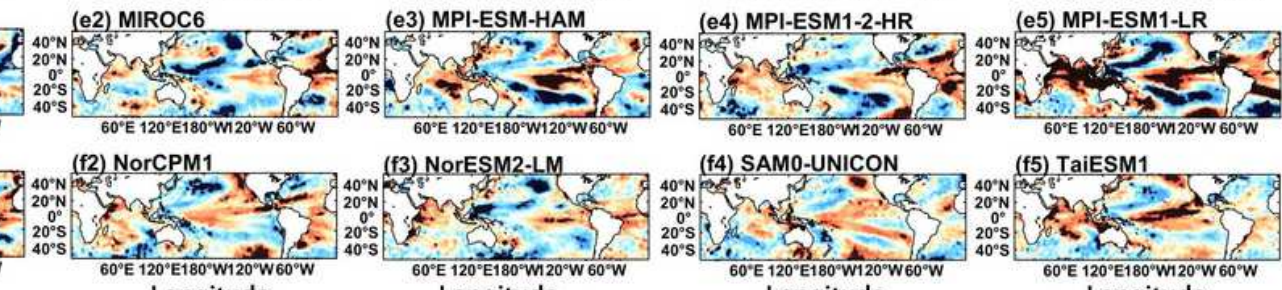

$20^{\circ} \mathrm{N}$
$20^{\circ} \mathrm{S}$
$40^{\circ} \mathrm{S}$

Longitude
Lo

(f5) TaiESM1

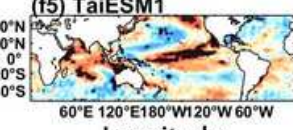

Longitude

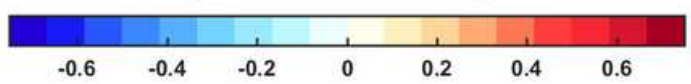

Figure 10 
The same as Fig. 9 but between the Meiyu precipitation averaged over the Meiyu area and the pre-spring Hadley-OI SST.
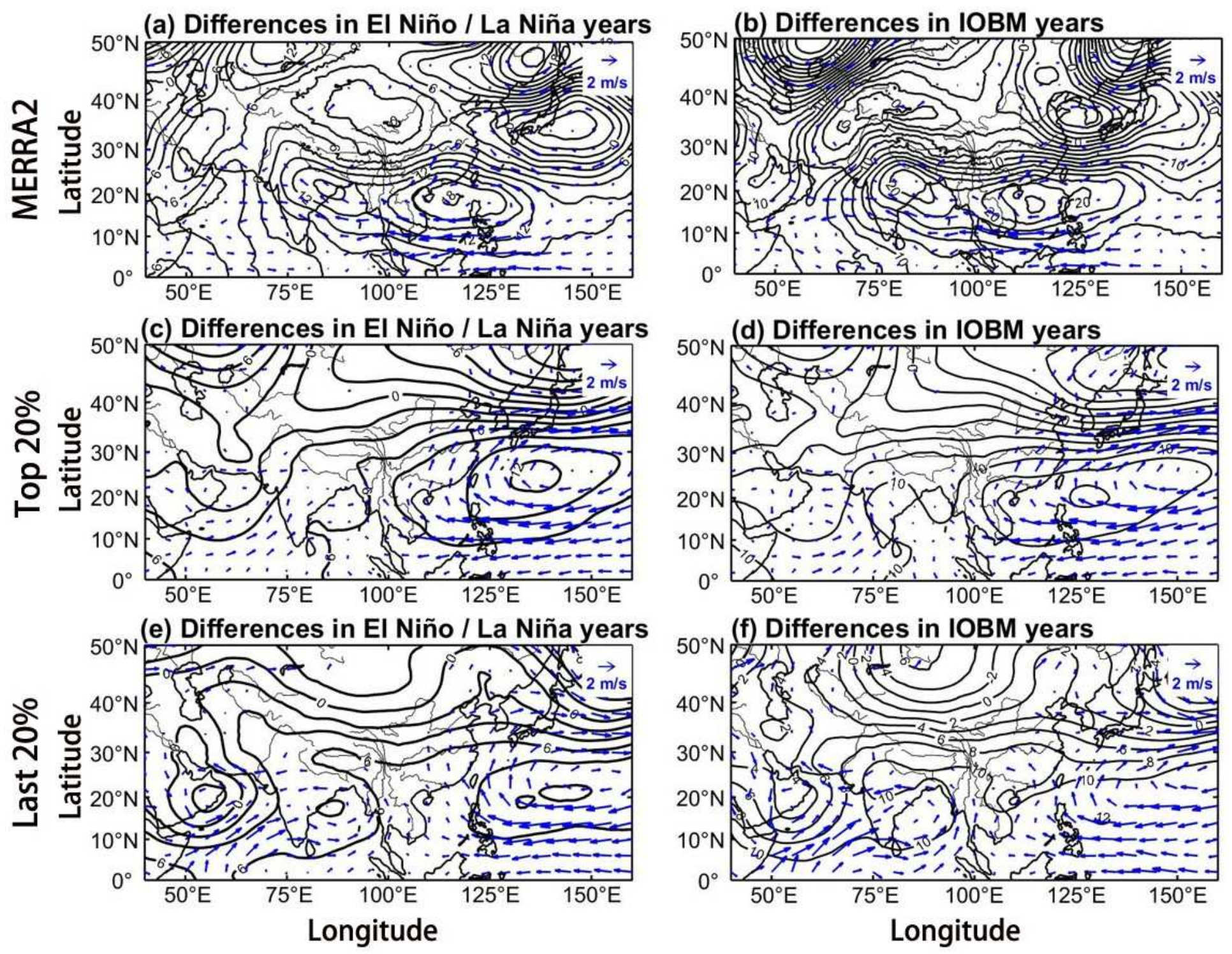

Figure 11

Differences in circulation fields between strong El Niño years and strong La Niña years ((a), (c), and (e)), and differences in circulation fields between warm IOBM years and cold IOBM years ((b), (d), and (f)) during the Meiyu season. The geopotential heights are at 500-hPa level, and contour intervals are $2 \mathrm{~m}$. The wind is at $850-\mathrm{hPa}$ level.

\section{Supplementary Files}

This is a list of supplementary files associated with this preprint. Click to download.

- CDfinalSI.docx 